\title{
RESEARCH ON RETAIL CHANNEL DECISIONS CONSIDERING CONSUMER'S FAIRNESS CONCERN
}

\author{
Mengli Huang, Yulin Zhang* and HaOwen Fan
}

\begin{abstract}
Online retailing provides alternative shopping channels, where the retail platform can either let manufacturers directly sell to consumers or open a self-operated channel, or even both. Regardless of sales channels, consumers often pay attention to the income gap between themselves and enterprises (named consumer's fairness concern). In this work, we explore how consumers' fairness concerns affect the optimal decisions of both manufacturer and retail platform under different retail channel modes (single-channel mode and mixed-channel mode). The results show that consumer's fairness concern has a negative impact on the retail price under low production cost in single-channel mode, while the retail prices in mix-channel mode are jointly determined by consumer's fairness concern and revenue sharing ratio. Besides, if the market channel mode has not yet formed, the retail platform can choose either a self-operated channel or manufacturer consignment channel, depending on the consumer's fairness concern level and revenue sharing ratio. By contrast, if the market channel mode has already been formed, the retail platform should make effort to reduce consumer's fairness concern if only the selfoperated channel exists, while maintain consumer's fairness concern and revenue sharing ratio at a moderate level if there exist mixed channels.
\end{abstract}

Mathematics Subject Classification. 91A40, 91B50.

Received December 31, 2020. Accepted November 21, 2021.

\section{INTRODUCTION}

With the rapid development of e-commerce, sales channels in the retail market have gradually diversified. There are two common sales channels: manufacturers' consignment channels and retail platforms' self-operated channels. The former is represented by online "official flagship stores" set up by brand owners [17]. In this channel, a retail platform provides the manufacturer with online sales media and offers a guarantee and supervision for both parties of the transaction, while the manufacturer provides product display, order fulfillment on the platform. For example, brands such as UNIQLO and ZARA will open flagship stores on Amazon, where the retail platform charges manufacturer slotting allowance and revenue sharing ratio [23,24]. The latter channel means that the retail platform wholesales products from the manufacturer and then sells to consumers directly. JD.COM, for example, has opened self-operated stores to enhance the platform image through high-quality logistics and services. If a retail platform opens a self-operated channel, it will inevitably compete with the manufacturer's consignment channel, and different market channel modes will form when they have different

Keywords. Consumer's fairness concern, single-channel-mode, mixed-channels-mode, Stackelberg game.

School of Economics and Management, Southeast University, Nanjing, P.R. China.

*Corresponding author: zhangyl@seu.edu.cn 
market forces [27]. The observation of channel diversification motivates the research about the pricing decisions of enterprises under different channel modes.

Most of the previous studies are based on the assumption that participants only care about their own benefits. However, behavioral economics research indicates that, in practice, consumers pay attention to both their own benefits and others' benefits [4], i.e., they will compare the benefits and test whether the distribution of benefits is fair, namely "fairness concern" [3,11]. Existing researches have pointed out there is a "horizontal fairness concern" between manufacturers and retail platforms, and both parties will feel disgusted due to the profits gap between themselves and the other $[18,30]$. Interestingly, consumers also show fairness concerns in their interactions with retail enterprises, namely "vertical fairness concern" [29]. When making a purchase decision, consumers will compare their benefits with that of sellers, and may give up purchasing when the benefit gap is large. Even if some transactions are beneficial to consumers, they will still sacrifice their utility to punish greedy sellers by abandoning deals or boycotting brands [12]. When multiple sales channels exist simultaneously, consumers face the problem of channel selection, and their purchasing utility in different channels is affected by their fairness concerns. However, few articles study the impact of consumers' fair concerns on the results of their channel selection and the pricing decisions and profits of all parties involved in the retail supply chain.

Considering that consumers' fairness concerns determine their purchasing utility and channel selection, in this work, we address how consumers' fairness concerns affect the pricing strategy and profits of the manufacturer and retail platform under different channel modes and further propose channel countermeasures for the manufacturer and retail platform. Furthermore, according to the existing retail scenarios in reality, three kinds of channel modes are investigated in detail, i.e., only manufacturer's consignment channel exists (single-channel mode); only retail platform's self-operated channel exists (single-channel mode); manufacturer's consignment channel and retail platform's self-operated channel coexist (mixed-channel mode). From the perspective of enterprises(manufacturer and retail platform), we intend to address the following research questions by considering consumers' fairness concerns: (1) What are the pricing decisions of manufacturer and retail platform under different channel structures? (2) What development strategies should manufacturer and retail platform take under different retail channel modes?

The main findings are as follows. First, when there is only a single channel in the market, the more consumers pay attention to transaction fairness, the more negative impact will be exerted on the retail prices when production cost is low. Second, the retail platform can guide the formation of market channel mode, depending on consumer's fairness concern level and the revenue sharing ratio. Besides, if the market channel mode has been formed, the retail platform should reduce consumer's fairness concerns by providing product discounts when there is only retail platform's self-operated channel. Third, When there are mixed channels, the retail platform can benefit from consumer's fairness concerns, if both consumer's fairness concern level and revenue sharing ratio are in a moderate range, otherwise, the retail platform will suffer from profit loss.

The remainder of the study is organized as follows. Section 2 reviews the most related studies. We present the model formulation and assumptions in Section 3. In Section 4, we present and discuss the equilibrium results of different channel modes. In Section 5, we verify the conclusions of Section 4 by numerical simulation and provide development strategies for the manufacturer and retail platform. Section 6 extends the current model. Concluding remarks are provided in Section 7. All the proofs are relegated to the Appendix A.

\section{LiterATURE REVIEW}

This paper is related to three main streams of research, i.e., retail channel mode, retail channel competition, and consumer's fairness concern on their shopping decision.

Retail channel mode. The existing literature has studied many different channel modes, including consignment channel, direct channel, self-operated channel and distributor channel [5,13,19,26,31]. Hagiu and Wright [9] investigate platform's channel choice between consignment channel and distributor channel and find that the platform should adopt distributor channel mode when marketing activities generate spillover effect between products. Chen et al. [2] study the decision-making problem of brand owner when both consignment and direct 
channels exist, and find that improving brand loyalty is beneficial to both brand owner and retail platform. Ryan et al. [22] point out the retail platform should sell products that compete with those offered by manufacturers when consumers have a strong preference for purchasing from the marketplace system. Tian et al. [25] investigate the supply chain composed of two competitive brand vendors and e-commerce platforms and conclude that the dealer (e-commerce platform) mode should be selected when the competitive intensity is high (low) while the mixed mode should be selected when the competitive intensity is moderate. Hendershott and Zhang [10] find that the direct sales channel will harm intermediaries, but benefit consumers, when the manufacturer's direct sales channel and consignment channel coexist. Liu and Ke [16] studies the channel selection strategy of brand owners based on consumer value, and finds that brand owners tend to choose single-channel mode when the utility discount coefficient is high, and tend to dual-channel mode when the discount coefficient is moderate. Most of the existing works analyze enterprises' choices of channel modes, but seldom consider how consumer's fairness concerns influence channel development strategies.

Retail channel competition. The sales channels developed by manufacturers and retail platforms result in channel competition [4]. Yao and Liu [28] study the Bertrand and Stackelberg competition models in the dualchannel supply chain, and points out that manufacturer could stimulate retailer to adopt online sales channel by setting a reasonable wholesale price. Kurata et al. [14] address the impact of brand competition on retail channel pricing decisions and find that channel price and profit increase with product substitution level. Li et al. [15] assume that retailers might provide value-added services to alleviate channel conflicts when taking dualchannel service competition and fairness concerns between retailers and manufacturers into consideration. Most of the previous studies on channel competition start from the perspective of retail enterprises, and construct the demand function by using "price substitution parameter" to reflect the intensity of channel competition. Instead, in our work, the consumer utility function is used to illustrate the consumer channel decision under the existence of channel competition.

Consumer's fairness concern. Consumer's fairness concern is widespread in the transaction process [1, 20]. Ferrer and Swaminathan [6] find that consumers pay great attention to the distribution of benefits and define it as a "fairness concern". The ultimatum experiment also verifies the widespread existence of consumer awareness of fairness [21]. Guo [7] argues that consumers' willingness to pay and utility will be reduced if they feel unfair. Kahneman [12] finds that even if certain transactions are beneficial to consumers, they may still give up transactions to express their dissatisfaction with unfairness. In addition, research on consumer psychology and behavior also shows that consumer's fairness concern will affect their purchasing decisions $[1,20]$. Other works consider that consumer's fairness concern plays a key role in the development strategy of enterprises. Guo and Jiang [8] study the influence of consumer's unfairness aversion on enterprises' optimal pricing and quality decisions through a game theory model. Yi et al. [29] explore how consumer's fairness concerns affect manufacturer's choice of distribution channel structure, and find that if consumers are very concerned about fairness, the manufacturer can reduce the dispersion of distribution channels through agent sales to get the maximum benefit. When consumers face multiple sales channels, the effectiveness of different channels due to fairness concerns will directly influence their decision-making. However, few existing studies consider channel selection and consumer fairness concerns simultaneously. This work focuses on the impact of consumer fairness concerns on pricing decisions and profits of the manufacture and retail platform under different channel structures.

\section{Model Setup}

There are two channels for consumers to purchase: manufacturer's consignment channel and retail platform's self-operated channel. Consumers usually face three possible channel modes while purchasing: (1) only manufacturer's consignment channel exists; (2) only retail platform's self-operated channel exists; (3) manufacturer's consignment channel and retail platform's self-operated channel coexist. This paper assumes that consumers are familiar with the channel structure, and their willingness to pay is internalized and directly affected by the channel mode. 
TABLE 1. Parameter assumptions and implications.

\begin{tabular}{ll}
\hline \hline Notation & Implication \\
\hline$p_{d}$ & Retail price of manufacturer's consignment channel (determined by manufacturer) \\
$p_{r}$ & Retail price of retail platform's self-operated channel (determined by retail platform) \\
$w$ & Wholesale price of the product \\
$U_{d}$ & Consumer's utility when purchasing through manufacturer's consignment channel \\
$U_{r}$ & Consumer's utility when purchasing through retail platform's self-operated channel \\
$\pi_{m}$ & Manufacturer's profit \\
$\pi_{r}$ & Retail platform's profit \\
$r$ & Revenue sharing ratio, $0<r<1$ (manufacturer pays to the retail platform) \\
$c$ & Unit product cost \\
$F$ & Slotting allowance \\
$v$ & Basic utility that consumer acquires from a single channel, $v \sim[0,1]$. \\
$\lambda$ & Consumer's sensitivity to fairness concern of the manufacturer or retail platform, reflecting con- \\
\hline
\end{tabular}

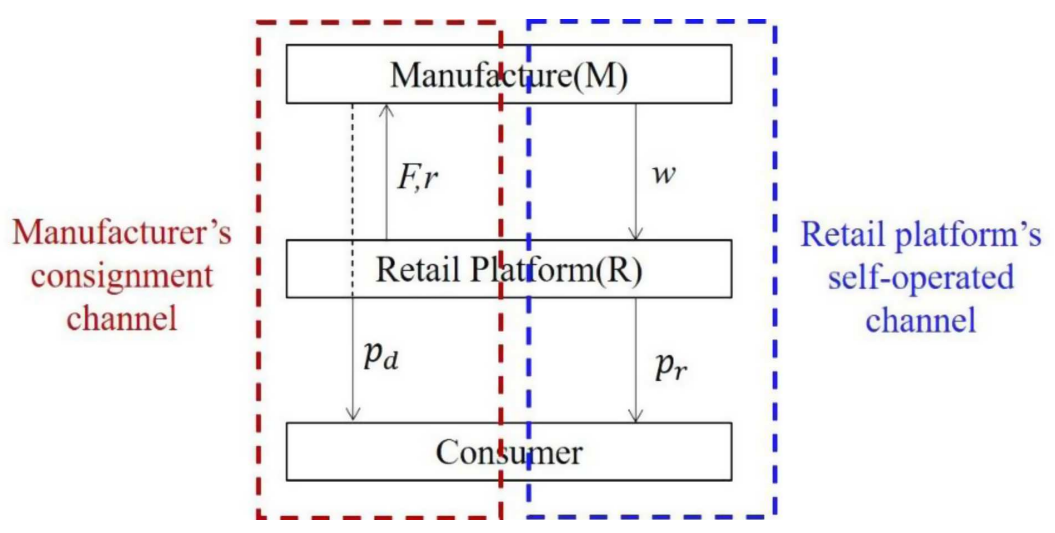

Figure 1. Conceptual model of multi-channel retail.

In the manufacturer's consignment channel, the manufacturer opens a flagship store on the retail platform. Retail platform charges manufacturer slotting allowance $F$ and revenue sharing ratio $r$. The retail price $p_{d}$ in the consignment channel is determined by the manufacturer, who sells products directly to consumers. In the self-operated channel, the manufacturer sells products to the retail platform at a wholesale price $w$, and the retail platform decides the retail price $p_{r}$ and sells products directly to consumers. The meanings of notations involved in this paper are shown in Table 1.

The involved subjects and channel conceptual model are shown in Figure 1.

In the consignment channel, manufacturer sells directly to consumers, who have fairness concerns about the manufacturer and retail platform simultaneously. While in the self-operated channel, consumers only have direct contact with the retail platform, so they only have fairness concerns about the retail platform. According to the model hypothesis of Yi [29], the effect of consumers' fairness concerns (hereafter referred to as "concerns") on their purchase utility comes from the income gap between consumers and enterprises. To be more exact, consumer's fairness focuses on how much they can get from one unit consumption and how much enterprises can earn from consumer's one unit consumption, and the gap between them, which is irrelevant to slotting allowance, as even if there is no consumption, the slotting allowance exists. Therefore, the utility functions $U_{d}$, $U_{r}$ of consumers in the consignment channel and the self-operated channel are shown in equations (3.1) and 
(3.2) respectively.

$$
\begin{aligned}
& U_{d}=v-p_{d}-\underbrace{\lambda\left\{\left[(1-r) p_{d}-c\right]-\left(v-p_{d}\right)\right\}}_{\text {fairness concern for manufacturer }}-\underbrace{\lambda\left[r p_{d}-\left(v-p_{d}\right)\right]}_{\text {fairness concern for retail platform }}=\left(c+2 v-3 p_{d}\right) \lambda+v-p_{d} \\
& U_{r}=v-p_{r}-\underbrace{\lambda\left[\left(p_{r}-w\right)-\left(v-p_{r}\right)\right]}_{\text {fairness concern for retail platform }}=\lambda\left(w+v-2 p_{r}\right)+v-p_{r} .
\end{aligned}
$$

When consumers have a non-negative purchase utility in a certain channel $\left(U_{d} \geq 0, U_{r} \geq 0\right)$, the demand will generate, i.e., $v \geq v_{d}=\frac{\left(3 p_{d}-c\right) \lambda+p_{d}}{2 \lambda+1}$, and $v \geq v_{r}=\frac{\left(2 p_{r}-w\right) \lambda+p_{r}}{\lambda+1}$.

The profit functions of manufacturer and retail platform under the three channel modes are different:

(1) When only consignment channel is available, profit functions of manufacturer and retail platform are shown in equations (3.3) and (3.4) respectively.

$$
\begin{aligned}
\pi_{m 1} & =\left[(1-r) p_{d}-c\right] D_{1}-F \\
\pi_{r 1} & =r p_{d} D_{1}+F .
\end{aligned}
$$

(2) When only a self-operated channel is available, manufacturer's profit comes from product wholesale, while the retail platform's profit comes from product sale. Therefore, profit functions of manufacturer and retail platform are shown in equations (3.5) and (3.6) respectively.

$$
\begin{aligned}
\pi_{m 2} & =(w-c) D_{2} \\
\pi_{r 2} & =\left(p_{r}-w\right) D_{2} .
\end{aligned}
$$

(3) When consignment channel and self-operated channel coexist, manufacturer's profit comes from the sum of income in consignment channel and product wholesale revenue in self-operated channel, while retail platform's profit comes from the profit sharing of manufacturer in consignment channel and product sale in the self-operated channel. Therefore, profit functions of manufacturer and retail platform are shown in equations (3.7) and (3.8) respectively.

$$
\begin{aligned}
\pi_{m 3} & =\left[(1-r) p_{d}-c\right] D_{3}+(w-c) D_{4}-F \\
\pi_{r 3} & =r p_{d} D_{3}+\left(p_{r}-w\right) D_{4}+F .
\end{aligned}
$$

\section{Analysis}

This section analyzes the optimal pricing and profits situation of manufacturer and retail platform under the three modes, and discusses development strategies of manufacturer and retail platform.

\subsection{Only the manufacturer's consignment channel exists}

When the financial strength of the retail platform is limited and the strength of the manufacturer is strong, there is only the manufacturer's consignment channel in the market. Brands such as Procter \& Gamble and Sony have opened flagship stores on LAZADA, allowing users to click on "lazmall" of its APP and go directly to the stores to make purchases. The basic utility $v$ obtained by consumers in purchasing products is evenly distributed on $[0,1]$, and the demand of consumers in the consignment channel can be obtained: $D_{1}=1-\frac{\left(3 p_{d}-c\right) \lambda+p_{d}}{2 \lambda+1}$. We relegate all the proofs to the Appendix A.

Proposition 4.1. When there is only the manufacturer's consignment channel in the market, let $A=$ $4(r-1)(3 \lambda+1)(2 \lambda+1)$, the optimal retail price, equilibrium profits of manufacturer and retail platform are shown in equations (4.1)-(4.3) respectively. 


$$
\begin{aligned}
p_{d 1}^{*}= & \frac{[(c+2) r-4 c-2] \lambda-c+r-1}{2(3 \lambda+1)(r-1)} \\
& \lambda^{2}\left[-\left(3 c^{2}+8 c+4\right) r^{2}-2\left(3 c^{2}+12 F-2 c-4\right) r+24 F+4 c-4\right]-r^{2}-2(2 F+c-1) r \\
\pi_{m 1}^{*}= & \frac{+\lambda\left[-4(c+1) r^{2}-2\left(2 c^{2}+10 F+c-4\right) r-2 c^{2}+20 F+6 c-4\right]-c^{2}+4 F+2 c-1}{A} \\
\pi_{r 1}^{*}= & \frac{\left[1+\left(3 c^{2}+8 c+4\right) \lambda^{2}+4(c+1) \lambda\right] r^{3}+2\left[-2\left(3 c^{2}-6 F+4 c+2\right) \lambda^{2}-\left(c^{2}-10 F+4 c+4\right) \lambda+2 F-1\right] r^{2}}{A(r-1)}
\end{aligned} .
$$

By analyzing the equilibrium price obtained in Proposition 4.1, Property 4.2 can be obtained.

Property 4.2. When only the manufacturer's consignment channel exists, the retail price decreases with concerns if the production cost is relatively low, and is always positively affected by the revenue sharing ratio, as well as the production cost.

As consumers become more concerned about transaction fairness, the manufacturer can lower the retail price of products with lower production costs and raise the retail price of products with higher production costs. This phenomenon is very common in reality. For example, the manufacturer often lowers the price to promote products of low-value products, and raises the price to enhance the user's image perception of highvalue products. This is because products with low production cost usually don't increase in value over time, and the mass production and production process are relatively simple. If consumers are haggling over the cheap products and pay attention to the fairness of the transaction process, sellers can only promote sales by lowering prices. Otherwise, consumers will quickly become less willing to buy, lower value goods will not be as attractive to them, and sellers will face the risk of overstocking. Indeed, low production costs could enhance consumers' perception of unfairness, but high production costs just do the reverse. When the revenue sharing ratio increases, the manufacturer will raise the retail price in order to retain higher profit, and this also applies to the condition when the product cost rises, as both a high revenue sharing ratio and a high production cost could mitigate consumers' perception of unfairness enhanced by the rise of price.

By analyzing the equilibrium profit of manufacturer obtained in Proposition 4.1, Property 4.3 can be obtained.

Property 4.3. When there is only manufacturer's consignment channel,

(1) Changes in manufacturer's profit with respect to concerns are affected by revenue sharing ratio and production cost. Let $\bar{c}_{1}=\frac{r-1}{4 r-3}, \bar{c}_{2}=1-r$.

(1) If $r$ and $c$ satisfies one of the following conditions: (a) $0<r<0.5$ or $0.75<r<1,0<c<\bar{c}_{1}$ or $c>\bar{c}_{2}$; (b) $0.5<r<0.75,0<c<\bar{c}_{2}$ or $c>\bar{c}_{1}$, manufacturer's profit is positively affected by concerns.

(2) If $r$ and $c$ satisfies one of the following conditions: (a) $0<r<0.5$ or $0.75<r<1, \bar{c}_{1}<c<\bar{c}_{2}$; (b) $0.5<r<0.75, \bar{c}_{2}<c<\bar{c}_{1}$, manufacturer's profit is negatively affected by concerns when $0<\lambda<\lambda_{2}$, and is positively affected when $\lambda_{2}<\lambda<1$.

(2) Changes in manufacturer's profit with respect to the revenue sharing ratio are affected by production cost. Let $B=\left[-2(3 c+4) r^{2}+4(3 c+4) r+12 c-8\right] \lambda^{2}-4\left(r^{2}-3 c-2 r+1\right) \lambda+2 c$. If $B>0$ and production cost is relatively low, manufacturer's profit is negatively affected by revenue sharing ratio. Otherwise, manufacturer's profit is positively affected. If $B<0$, changes in manufacturer's profit with respect to revenue sharing ratio is opposite to that of the situation $B>0$.

(3) The manufacturer's profit is firstly decreasing and then increasing in the production cost, i.e., if $c<$ $\frac{(1-r)(2 \lambda+1)(2 \lambda r+\lambda+1)}{3 \lambda^{2} r^{2}+6 \lambda^{2} r+4 \lambda r+2 \lambda+1}$, manufacturer's profit is negatively affected by production cost. Otherwise, the manufacturer's profit is positively affected by production cost.

(4) The slotting allowance always shows a negative effect on the manufacturer's profit. 
According to Property 4.3, manufacturer should guide consumers to pay attention to transaction fairness for products with extremely low or extremely high production costs. Consumers can be encouraged to pay attention to trade fairness by disclosing product price trends. Regardless of the revenue sharing ratio, as long as the production cost is moderate, manufacturer's profit will always be negatively affected by concerns when the concern level is low. Otherwise, manufacturer's profit will increase. In reality, when consumers start to pay attention to transaction fairness, manufacturer's countermeasures are usually not perfect. When consumer's concern behavior becomes a consensus, the manufacturer will improve its service level and product quality of consignment channel due to consumer's behavior, thus improving the brand image and generating a positive impact on profits. The manufacturer doesn't need to resist retail platform increasing revenue sharing ratio. When $B>0$ and production cost is high or $B<0$ and production cost is low, manufacturer can accept retail platform to increase the sharing ratio. In addition, it seems that both an extremely low production cost and an extremely high production cost are beneficial to the manufacturer, but the slotting allowance always hurts it. As discussed above, low production costs and low revenue sharing ratios could enhance the perception of unfairness but increase the manufacturer's profit.

By analyzing the equilibrium profit of retail platform obtained in Proposition 4.1, Property 4.4 can be obtained.

Property 4.4. When there is only manufacturer's consignment channel,

(1) Changes in retail platform's profit with respect to concerns are affected by revenue sharing ratio and production cost. Let $C=3\left(5 r^{2}-16 r+8\right) \lambda^{2}+6\left(r^{2}-4 r+2\right) \lambda-2 r+1$.

(1) If $C>0$, when production cost is relatively low, retail platform's profit is negatively affected by concerns, otherwise, it is positively affected.

(2) If $C<0$, when $c>-\frac{2(2 \lambda+1)^{2}(r-1)^{2}}{C}$, retail platform's profit is positively affected by concerns when production cost is moderate, otherwise, it is negatively affected. When $c<-\frac{2(2 \lambda+1)^{2}(r-1)^{2}}{C}$, retail platform's profit is negatively affected by concerns when production cost is moderate, otherwise, it is positively affected.

(2) Changes in retail platform's profit with respect to revenue sharing ratio are affected by production cost. It is positively affected by revenue sharing ratio when production cost is moderate, otherwise, it is negatively affected.

(3) The retail platform's profit is firstly increasing and then decreasing in the production cost. If $c<$ $\frac{2 \lambda(1-r)^{2}(2 \lambda+1)}{(3 \lambda r+1)[(4-r) \lambda-1]}$, retail platform's profit is positively affected by production cost. Otherwise, retail platform's profit is negatively affected by production cost.

(4) The slotting allowance always show a positive effect on retail platform's profit.

Concerns can exert a positive influence on retail platform's profit under certain conditions. When $C>0$ and production cost is high, retail platform can encourage consumers to pay attention to transaction fairness. When $C<0$ and $c>-\frac{2(2 \lambda+1)^{2}(r-1)^{2}}{C}$, retail platform should guide consumers to raise awareness of fair trade when production cost is moderate. When $C<0$ and $c<-\frac{2(2 \lambda+1)^{2}(r-1)^{2}}{C}$, retail platform should reduce consumers' concerns of transactions by not disclosing retail price trends or other measures when production cost is moderate. The retail platform should not blindly increase the revenue sharing ratio, i.e., when production cost is extremely low or extremely high, increasing revenue sharing ratio will reduce its profit. In the real retail market, if the manufacturer sells products with low value and the retail platform charges an excessively high revenue share, it will greatly frustrate the manufacturer's sales enthusiasm. If the manufacturer sells high-value products, it has a higher voice at this time. The excessive increase in the revenue sharing ratio of retail platform will cause manufacturer's strong dissatisfaction. Both situations will have negative impacts on the profits of the retail platform. Besides, both production cost and slotting allowance generate opposite impacts on the retail platform's profits, as compared to the impacts on the manufacture's profit. 


\subsection{Only the retail platform's self-operated channel exists}

When the financial strength of the retail platform is strong, and the manufacturer is a small or mediumsized enterprise, the retail platform often develops a self-operated channel, and the manufacturer only needs to wholesale products to the retail platform to make a profit. One of the most common self-operated retail platforms is JD.com. Most of its businesses are self-operated. JD.com can effectively control consumers' satisfaction by providing services such as product selection, pricing, sales, self-built logistics and after-sales services. This can not only reduce online sales costs of small manufacturers, but also help the retail platform to form scale economies.

The demand function of consumers in retail platform's self-operated channel is $D_{2}=1+\frac{\left(w-2 p_{r}\right) \lambda-p_{r}}{\lambda+1}$. In this case, the retail platform is the dominant player in the Stackelberg game, deciding the retail price $p_{r}$ first and the manufacturer then decides the wholesale price $w$. Let $p_{r}=w+m$, where $m$ is the marginal profit.

Proposition 4.5. When only the retail platform's self-operated channel exists, the optimal wholesale price and retail price are shown in equations (4.4) and (4.5) respectively.

$$
\begin{aligned}
w_{2}^{*} & =\frac{3 c+1}{4} \\
p_{r 2}^{*} & =\frac{4 \lambda(c+1)+c+3}{8 \lambda+4} .
\end{aligned}
$$

The equilibrium profits of manufacturer and retail platform are shown in equations (4.6) and (4.7) respectively.

$$
\begin{aligned}
\pi_{m 2}^{*} & =\frac{(c-1)^{2}}{16} \\
\pi_{r 2}^{*} & =\frac{(\lambda+1)(c-1)^{2}}{16 \lambda+8} .
\end{aligned}
$$

By analyzing the equilibrium solution in Proposition 4.5, Property 4.6 can be obtained.

Property 4.6. When there is only retail platform's self-operated channel,

(1) The wholesale price and manufacturer's profit will not be affected by concerns. The retail price will be negatively affected by concerns when production cost is low, otherwise, it will be positively affected. The retail platform's profit always decreases with concerns.

(2) The wholesale price and retail price always increase with the production cost, while the profits of the manufacturer and retail platform increase with the production cost when $c>1$ and decrease with it when $0<c<1$.

When there is only retail platform's self-operated channel in the market, consumers only have fairness concerns about the retail platform, so manufacturer's wholesale price and profit are not affected by concerns. It is unacceptable if the retail platform raises the retail price of low-value products. Therefore, when production cost is low, the retail price will decrease if concerns increase. However, if production cost is high, the retail platform should raise the retail price to make up the wholesale expenditure even though consumers are more and more concerned about trade fairness. Due to the retail platform giving profit to consumers to promote consumption, its profit will decrease. The retail platform should reduce concerns by offering product discounts or improving the service level in the self-operated channel. In this case, the production cost demonstrates the same effect on the manufacture's profit and the retail platform's profit. In practice, low production costs represent low wholesale prices, and wholesale prices could increase consumers' unfairness. As a result, both the profits of the manufacturer and retail platform decrease under low production costs but increase under high production costs.

Combining formulas (4.2), (4.3), (4.6) and (4.7), Lemma 4.7 can be obtained.

Lemma 4.7. If there is only a single channel in the retail market, 
(1) Manufacturer should actively open up the consignment channel when slotting allowance is low than the threshold $\bar{F}_{1}$, and refuse to wholesale products to the retail platform simultaneously. When the slotting allowance is high, the consignment channel should be abandoned by the manufacturer, and all products should be wholesaled to retail platform.

(2) Retail platform should actively open the self-operated channel when the proposed slotting allowance is low than the threshold $\bar{F}_{2}$, and prevent the manufacturer from consignment; otherwise, it should abandon selfoperating and encourage the manufacturer to consign.

According to Lemma 4.7, if there is only a single channel in the market, the manufacturer and retail platform tend to choose different channel modes in most situations of slotting allowance, and the final channel mode is influenced by the market forces of both sides. Therefore, the manufacturer and retail platform need to consider slotting allowance when determining whether to open a consignment channel or a self-operated channel.

\subsection{Manufacturer's consignment channel and retail platform's self-operated channel coexist}

The most common phenomenon in real life is that manufacturer opens flagship stores on a retail platform while the retail platform is also self-operated, and consumers can buy from both channels simultaneously. For example, TMALL has both flagship stores opened by manufacturers and self-operated stores such as "TMALL Supermarket". In this mode, manufacturer and retail platform decide product price $p_{d}$ and $p_{r}$ at the same time respectively, and then manufacturer decides the wholesale price $w$.

When $U_{d}=U_{r}$, that is, $v_{d r}=\frac{\left(w+3 p_{d}-2 p_{r}-c\right) \lambda+p_{d}-p_{r}}{\lambda}$, there is no difference in the purchasing utility of consumers in the two channels. When $v>v_{d r}, U_{d}>U_{r}$. According to the principle of personal rationality and incentive compatibility, the segmented demand functions of consumers in the manufacturer's consignment channel and retail platform's self-operated channel under the mixed-channel mode are shown in equations (4.8) and (4.9).

$$
\begin{aligned}
& D_{3}= \begin{cases}1-\frac{\left(w+3 p_{d}-2 p_{r}-c\right) \lambda+p_{d}-p_{r}}{\lambda} & \text { if } p_{d} \geq \frac{\left(c-2 w+4 p_{r}\right) \lambda^{2}+\left(c-w+4 p_{r}\right) \lambda+p_{r}}{(3 \lambda+1)(\lambda+1)} \\
1-\frac{\left(3 p_{d}-c\right) \lambda+p_{d}}{2 \lambda+1} & \text { if } 0<p_{d}<\frac{\left(c-2 w+4 p_{r}\right) \lambda^{2}+\left(c-w+4 p_{r}\right) \lambda+p_{r}}{(3 \lambda+1)(\lambda+1)}\end{cases} \\
& D_{4}= \begin{cases}\frac{\left(w+3 p_{d}-2 p_{r}-c\right) \lambda+p_{d}-p_{r}}{\lambda}-\frac{\left(2 p_{r}-w\right) \lambda+p_{r}}{\lambda+1} & \text { if } p_{d} \geq \frac{\left(c-2 w+4 p_{r}\right) \lambda^{2}+\left(c-w+4 p_{r}\right) \lambda+p_{r}}{(3 \lambda+1)(\lambda+1)} \\
0 & \text { if } 0<p_{d}<\frac{\left(c-2 w+4 p_{r}\right) \lambda^{2}+\left(c-w+4 p_{r}\right) \lambda+p_{r}}{(3 \lambda+1)(\lambda+1)} .\end{cases}
\end{aligned}
$$

Since there is demand in both channels, $p_{d} \geq \frac{\left(c-2 w+4 p_{r}\right) \lambda^{2}+\left(c-w+4 p_{r}\right) \lambda+p_{r}}{(3 \lambda+1)(\lambda+1)}$ should be satisfied. The demand functions in manufacturer's consignment channel and retail platform's self-operated channel are shown in equations (4.10) and (4.11) respectively.

$$
\begin{aligned}
& D_{3}=1-\frac{\left(w+3 p_{d}-2 p_{r}-c\right) \lambda+p_{d}-p_{r}}{\lambda} \\
& D_{4}=\frac{\left(w+3 p_{d}-2 p_{r}-c\right) \lambda+p_{d}-p_{r}}{\lambda}-\frac{\left(2 p_{r}-w\right) \lambda+p_{r}}{\lambda+1} .
\end{aligned}
$$

Substituting equations (4.10) and (4.11) into formulas (3.7) and (3.8), Proposition 4.8 can be obtained.

Proposition 4.8. When the manufacturer's consignment channel and retail platform's self-operated channel coexist in the market, let $D=(\lambda+1) r^{2}-(24 \lambda+10) r+20 \lambda+8$, so that, the optimal wholesale price and retail prices in consignment channel and self-operated channel are shown in equations (4.12)-(4.14) respectively.

$$
w_{3}^{*}=\frac{(r-1)\left\{[(13 c+10) r-34 c-12] \lambda^{2}+[13(c+1) r-26 c-14] \lambda+2(c+2) r-4 c-4\right\}}{(2 \lambda+1) D}
$$




$$
\begin{aligned}
p_{d 3}^{*}= & \frac{-2 r[(5 c+4) \lambda+c+2]+8(2 c+1) \lambda+4(c+1)}{D} \\
p_{r 3}^{*}= & \frac{\left[(9 c+8) r^{2}-8(4 c+5) r+4(11 c+8)\right] \lambda^{3}+\left[(7 c+10) r^{2}-(23 c+62) r+50 c+52\right] \lambda^{2}}{(2 \lambda+1)^{2} D} .
\end{aligned}
$$

The equilibrium profits of manufacturer and retail platform are shown in equations (4.15) and (4.16) respectively.

$$
\begin{aligned}
\pi_{m 3}^{*} & =\frac{a_{1} r^{4}+a_{2} r^{3}+a_{3} r^{2}+a_{4} r+a_{5}}{(2 \lambda+1) D^{2}} \\
\pi_{r 3}^{*} & =\frac{b_{1} \lambda^{4}+b_{2} \lambda^{3}+b_{3} \lambda^{2}+b_{4} \lambda+b_{5}}{(2 \lambda+1)^{2} D^{2}} .
\end{aligned}
$$

The expressions of $a_{1} \sim a_{5}, b_{1} \sim b_{5}$ are shown in Appendix A.

By comparing the equilibrium prices of both channels in Proposition 4.8, we can obtain Lemma 4.9.

Lemma 4.9. When the manufacturer's consignment channel and retail platform's self-operated channel coexist in the market, let $E=\left(9 r^{2}+8 r-20\right) \lambda^{2}+\left(7 r^{2}+25 r-30\right) \lambda+11 r-10$,

(1) when $\frac{E}{D}<0$, if production cost is low, the retail price in manufacturer's consignment channel is lower than that in retail platform's self-operated channel; otherwise, the retail price in self-operated channel is higher; (2) when $\frac{E}{D}>0$, the relative size of the retail prices in both channels is opposite to that of the situation $\frac{E}{D}<0$.

When determining the retail prices, manufacturer and retail platform need to consider the influence of concerns, revenue sharing ratio and production cost.

By analyzing the equilibrium price obtained in Proposition 4.8, Property 4.10 can be obtained.

Property 4.10. When the manufacturer's consignment channel and retail platform's self-operated channel coexist in the market, let

$$
\begin{aligned}
G= & 2\left(22 r^{4}-154 r^{3}-43 r^{2}+76 r+36\right) \lambda^{3}+4\left(10 r^{4}-19 r^{3}-93 r^{2}+28 r+44\right) \lambda^{2} \\
& 2\left(2 r^{4}+22 r^{3}-67 r^{2}-44 r+68\right) \lambda+4\left(r^{3}+2 r^{2}-12 r+8\right), \\
H= & 2\left(-34 r^{4}+493 r^{3}-380 r^{2}-388 r+48\right) \lambda^{4}+2\left(-64 r^{4}+551 r^{3}-62 r^{2}-908 r+120\right) \lambda^{3} \\
& +2\left(-34 r^{4}+143 r^{3}+320 r^{2}-716 r+96\right) \lambda^{2}+2\left(-4 r^{4}-15 r^{3}+162 r^{2}-212 r+24\right) \lambda-8 r(2-r)^{2} .
\end{aligned}
$$

(1) Changes of the retail price in the consignment channel with respect to concerns are affected by the revenue sharing ratio and production cost. With the increase of concerns, when $0<r<2 \sqrt{2}-2$, the retail price increases if $c>\frac{-r^{2}-4 r+4}{2 r^{2}-14 r+12}$, and decreases if $0<c<\frac{-r^{2}-4 r+4}{2 r^{2}-14 r+12}$. The retail price always increases when $2 \sqrt{2}-2<r<1$.

(2) Retail price in the consignment channel is always positively affected by the revenue sharing ratio, as well as the production cost.

(3) Changes of manufacturer's profit with respect to production cost are affected by concerns, so are changes of retail platform's profit with respect to production cost. When $G>0$, the manufacturer's profit is firstly decreasing and then increasing in the production cost; when $G<0$, the manufacturer's profit is firstly increasing and then decreasing in the production cost. When $H>0$, the retail platform's profit is firstly decreasing and then increasing in the production cost; when $H<0$, the retail platform's profit is firstly increasing and then decreasing in the production cost.

(4) The slotting allowance always shows opposite effects on manufacturer's profit and retail platform's profit, i.e., a negative effect on manufacturer's profit but a positive effect on retail platform's profit. 


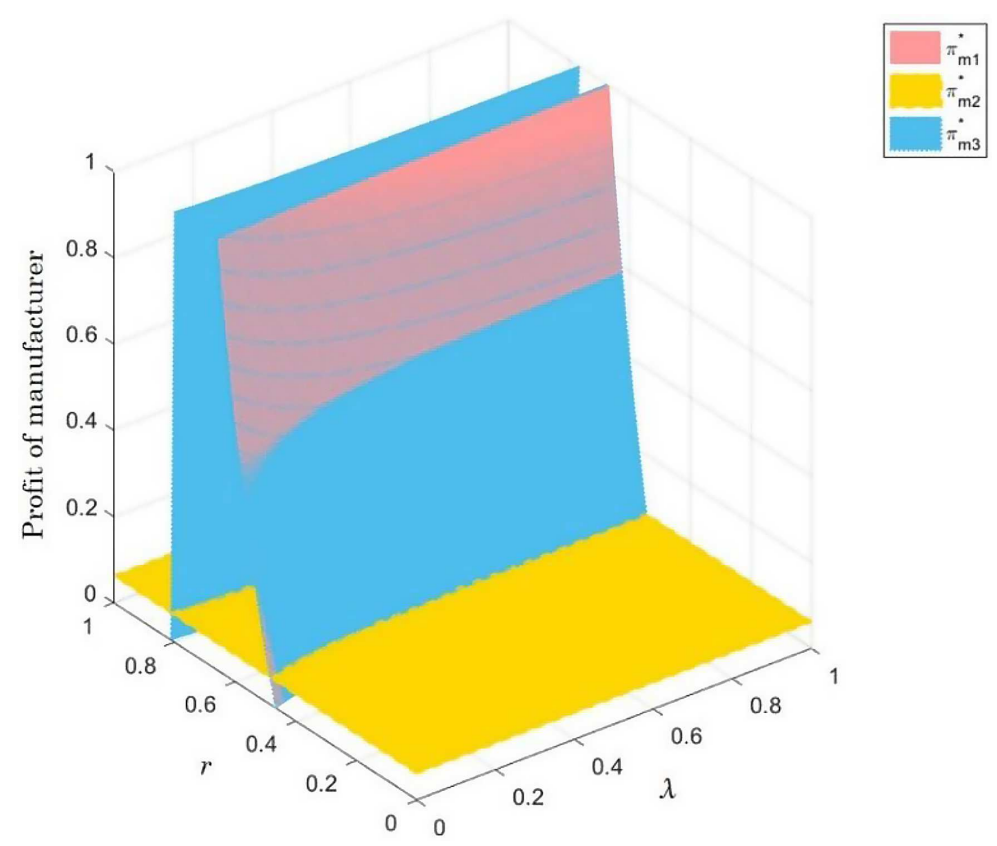

Figure 2. Manufacturer's profit situation when $r$ and $\lambda$ change.

A low revenue sharing ratio allows the manufacturer to raise the retail price on higher-cost products when consumers are increasingly concerned about trade fairness, because a slight increase in the price of higher-value products does not cause a backlash. Simultaneously, retail prices of products with lower production costs will be reduced to increase sales. If the revenue sharing ratio is high, the manufacturer shares a bigger share of profit with retail platform. Therefore, the manufacturer will raise the retail price to make more profit even if consumers are more concerned about fair trade. In addition, if the revenue sharing ratio charged by the retail platform increases, the manufacturer tends to increase retail price in order to make up for the lost profit in the consignment channel. In mix-channel mode, due to consumer's channel comparison, the effects of production cost on both the manufacture's profit and the retail platform's profit are ambiguous. However, the impacts of slotting allowance are straightforward, i.e., it always hurts the manufacture but benefits the retail platform.

\section{NumeriCAL SIMUlation}

The above research mainly considers the profits of manufacturers and retail platforms when a single factor changes. While in the real retail market, $r$ and $\lambda$ often change simultaneously. Combined with numerical examples, this section visually demonstrates the impact of consumer's fairness concern and revenue sharing ratio on the profits of manufacturers and retail platforms under different channel modes, so as to verify the theoretical conclusions in Section 4 and provide development strategies for manufacturer and retail platform.

\subsection{Situation of manufacturer's profit when $r$ and $\lambda$ change simultaneously}

Let $c=2, F=1$, Figures 2 and 3 shows the manufacturer's profit under different retail market modes when $r$ and $\lambda$ change.

When the retail market is a single-channel mode, if "only consignment channel exists", when $r=0.3$, $\lambda=0.5$, we can get $\bar{c}_{1}=0.39, \bar{c}_{2}=0.7, \bar{c}_{3}=0.77, B=21.57 . \pi_{m 1}^{*}$ increases when $\lambda$ or $r$ increases. The numerical simulation result is consistent with Property 4.3. If "only self-operated channel exists", $\pi_{m 2}^{*}$ isn't 


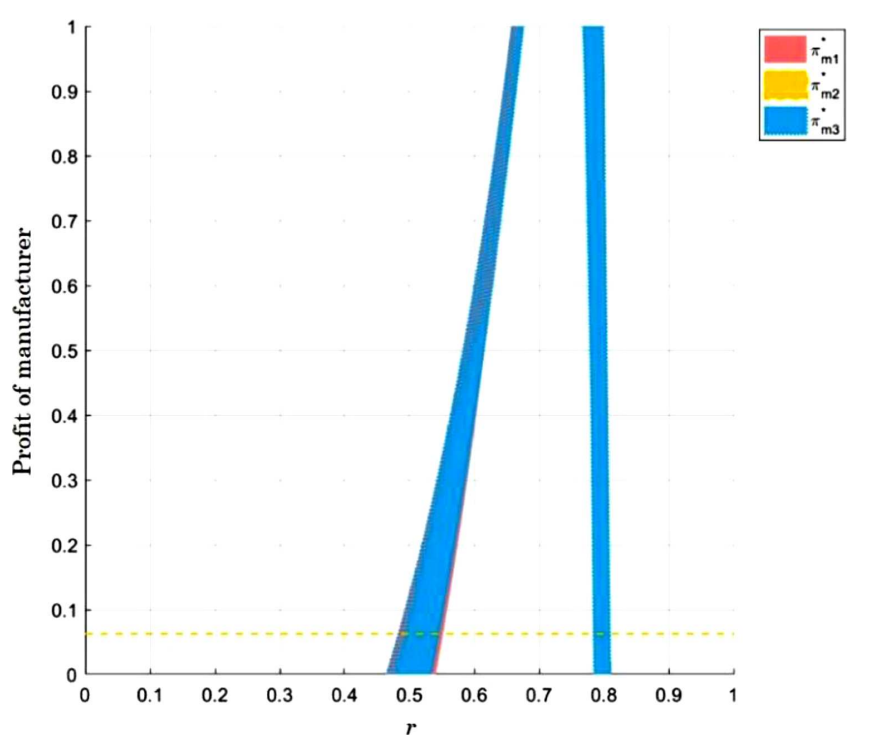

FIGURE $3 . r-\pi_{m i}^{*}$ view of manufacturer's profit situation when $r$ and $\lambda$ change.

affected by $\lambda$ or $r$. The numerical simulation result is consistent with Property 4.6. At this time, $F>\bar{F}_{1}=0.25$ and $\pi_{m 1}^{*}<\pi_{m 2}^{*}$. The numerical simulation result is consistent with Lemma 4.7.

When the retail market is mixed-channels-mode, $\pi_{m 3}^{*}$ is negatively affected by $\lambda$, and increases first and then decreases with $r$ in this numerical example.

\subsection{Situation of retail platform's profit when $r$ and $\lambda$ change simultaneously}

Let $c=2, F=1$, Figures 4 and 5 shows the retail platform's profit under different retail market modes when $r$ and $\lambda$ change.

When the retail market is a single-channel mode, if "only consignment channel exists", when $r=0.3, \lambda=0.5$, $C=5.81, \bar{c}_{5}=-1.57, \bar{c}_{6}=0.22$. Because of $c>\bar{c}_{6}, \pi_{r 1}^{*}$ increases when $\lambda$ increases. Meanwhile, $\bar{c}_{8}=0.6$, $\bar{c}_{9}=0.32$. Because $c>\bar{c}_{8}, \pi_{r 1}^{*}$ decreases when $r$ increases. The numerical simulation result is consistent with Property 4.4. If "only self-operated channel exists", $\pi_{r 2}^{*}$ decreases slightly with the increase of $\lambda$, and is not affected by $r$. The numerical simulation result is consistent with Property 4.6. At this time, $F>\bar{F}_{2}=0.72$ and $\pi_{r 1}^{*}>\pi_{r 2}^{*}$. The numerical simulation result is consistent with Lemma 4.7.

When the retail market is a mixed-channel mode, $\pi_{r 3}^{*}$ increases first and then decreases with $\lambda$, and is negatively affected by $r$ in this numerical example.

Based on the above analysis in Sections 5.1 and 5.2, channel measures can be obtained.

(1) If the market channel mode is immature (the mode hasn't yet formed), the manufacturer and retail platform can actively promote the channel mode.

- From the perspective of the manufacturer, when the levels of $r$ and $\lambda$ are both low, the manufacturer should cancel flagship stores and simply wholesale products. Otherwise, the manufacturer should open flagship stores and refuse to wholesale products to the retail platform.

- From the perspective of retail platform, if the manufacturer has not opened up consignment channel initially, when the levels of $r$ and $\lambda$ are both low, the retail platform can provide relevant preferential measures for the manufacturer to enter the platform and give up self-operation; when the levels of $r$ and $\lambda$ are both high, the retail platform can directly open up a self-operated channel and prevent manufacturer's consignment behavior. 


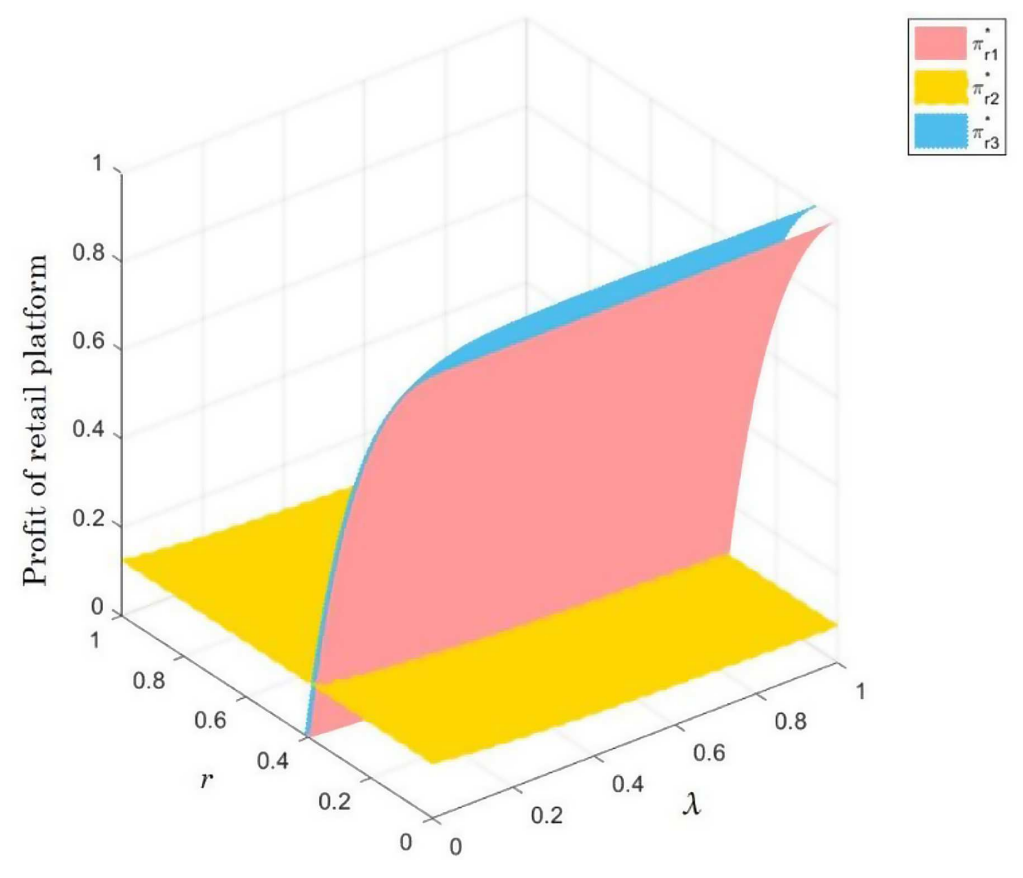

Figure 4. Retail platform's profit situation when $r$ and $\lambda$ change.

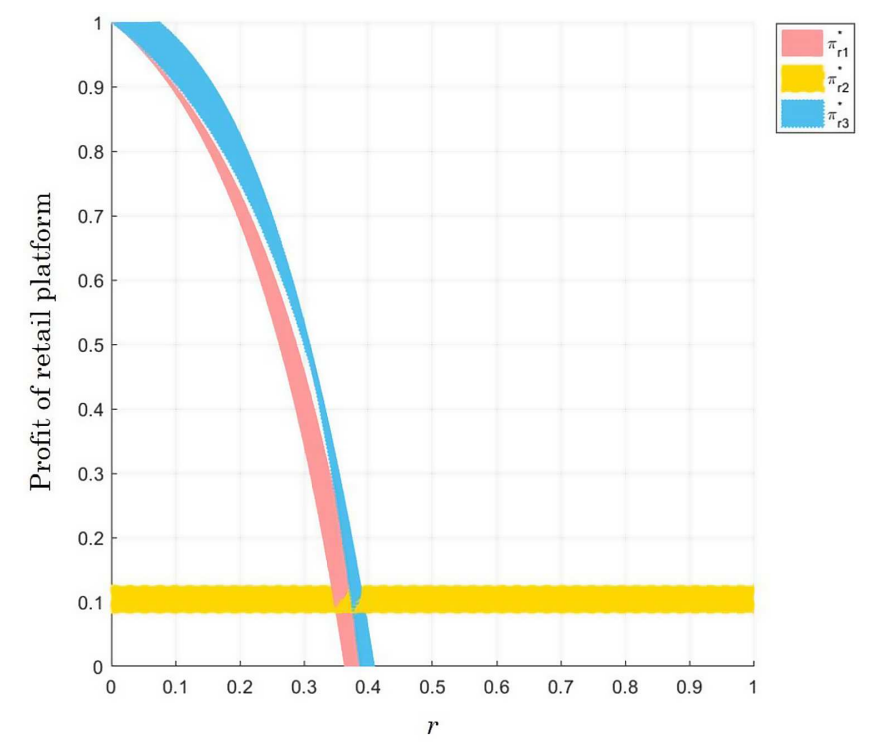

FiguRe 5. $r-\pi_{r i}^{*}$ view of retail platform's profit situation when $r$ and $\lambda$ change. 
- Manufacturer and retail platform prefer different channel modes under most combinations of $r$ and $\lambda$. Both parties should strengthen their own strength and market voice to facilitate the above channel countermeasures.

(2) If the market channel model is mature (the mode has formed), the retail platform can adjust the concern level and revenue sharing ratio according to the channel mode.

If there is "only self-operated channel", the retail platform can take measures such as coupon distribution and customized services to reduce concerns as far as possible. If the retail market is mixed-channels-mode, retail platform should control concern level within a moderate range, otherwise, it will lead to a decrease in profit or even loss.

\section{MODEL EXTENSION}

In practice, consumers may have different fairness concerns about the manufacturer and retail platform. If so, the utility functions of consumers in the consignment channel and the self-operated channel can be written as shown in equations (6.1) and (6.2), respectively, where $\lambda_{1}$ and $\lambda_{2}$ measure consumer's sensitivity to fairness concern of the manufacturer and retail platform.

$$
\begin{aligned}
& U_{d}=v-p_{d}-\underbrace{\lambda_{1}\left\{\left[(1-r) p_{d}-c\right]-\left(v-p_{d}\right)\right\}}_{\text {fairness concern for manufacturer }}-\underbrace{\lambda_{2}\left[r p_{d}-\left(v-p_{d}\right)\right]}_{\text {fairness concern for retail platform }} \\
& U_{r}=v-p_{r}-\underbrace{\lambda_{2}\left[\left(p_{r}-w\right)-\left(v-p_{r}\right)\right]}_{\text {fairness concern for retail platform }}=\lambda_{2}\left(w+v-2 p_{r}\right)+v-p_{r} .
\end{aligned}
$$

\subsection{Only the manufacturer's consignment channel exists}

When there is only manufacturer's consignment channel in the market, the optimal retail price, equilibrium profits of manufacturer and retail platform are shown as

$$
\begin{aligned}
p_{d 1}^{*}= & \frac{[c(3-2 r)+1-r] \lambda_{1}+[c(1+r)+1-r] \lambda_{2}-r+c+1}{2\left[1+(2-r) \lambda_{1}+(1+r) \lambda_{2}\right](1-r)} \\
\pi_{m 1}^{*}= & \frac{\left\{(c+r-1)\left(\lambda_{1}+1\right)+\lambda_{2}[(c+1) r+c-1]\right\}^{2}}{4\left(\lambda_{1}+\lambda_{2}+1\right)\left[1+(2-r) \lambda_{1}+(1+r) \lambda_{2}\right](1-r)}-F \\
\pi_{r 1}^{*}= & \frac{r\left\{(c+r-1)\left(\lambda_{1}+1\right)+\lambda_{2}[(c+1) r+c-1]\right\}\left\{(1-r)\left(\lambda_{1}+\lambda_{2}+1\right)+c\left[\left(-2 \lambda_{1}+\lambda_{2}\right) r+3 \lambda_{1}+\lambda_{2}+1\right]\right\}}{4\left(\lambda_{1}+\lambda_{2}+1\right)(1-r)^{2}\left[-1-(2-r) \lambda_{1}-(1+r) \lambda_{2}\right]} \\
& +F
\end{aligned}
$$

It indicates that consumer's fairness concerns about manufacturer and retail platform have different effects on the retail price, i.e., for a low production cost, consumer's concerns about manufacturer decrease the retail price, but consumer's concerns about retail platform raise the retail price; for a high production cost, consumer's concerns about manufacturer raise the retail price, but consumer's concerns about retail platform decrease the retail price. If consumers pay attention to the manufacturer, they will naturally think that the production cost of a low-value product is low, and when the manufacturers raise the retail price, they will think that the transaction is not worth it. However, if consumers pay attention to the benefits of retail platforms, their perception of production cost will not be particularly obvious. When retail platforms attract attention, appropriately raising the retail price of commodities may not significantly reduce the number of transactions. For high-value goods, consumers will allow manufacturers to raise retail prices. Besides, if retail platforms with high-value goods continue to increase the retail price, it will let consumers consider the existence of additional cost of goods (marketing costs). Because the consumers' perception of production cost is not obvious, consumers' willingness to pay will decrease. In terms of manufacturer's (retail platform's) profit, consumer's fairness concerns about 
manufacturer and retail platform both show ambiguous effects, i.e., consumer's fairness concerns about manufacturer and retail platform may increase or decrease manufacturer's (retail platform's) profit, depending on production cost and revenue sharing ratio (see Appendix A for more details).

\subsection{Only retail platform's self-operated channel exists}

When there is only retail platform's self-operated channel in the market, the equilibrium wholesale price, retail price, and profits of the manufacturer and retail platform are shown as

$$
\begin{aligned}
w_{2}^{*} & =\frac{3 c+1}{4}, \\
p_{r 2}^{*} & =\frac{4 \lambda_{2}(c+1)+c+3}{8 \lambda_{2}+4}, \\
\pi_{m 2}^{*} & =\frac{(c-1)^{2}}{16} \\
\pi_{r 2}^{*} & =\frac{\left(\lambda_{2}+1\right)(c-1)^{2}}{16 \lambda_{2}+8} .
\end{aligned}
$$

Similarly, the slotting allowance determines the channel choice of both manufacturer and retail platform, i.e., if $F<\left(\frac{\left\{(c+r-1)\left(\lambda_{1}+1\right)+\lambda_{2}[(c+1) r+c-1]\right\}^{2}}{4\left(\lambda_{1}+\lambda_{2}+1\right)\left[1+(2-r) \lambda_{1}+(1+r) \lambda_{2}\right](1-r)}-\frac{(c-1)^{2}}{16}\right)^{+}$, the manufacturer will open up a consignment channel; if $F>\left(\frac{\left(\lambda_{2}+1\right)(c-1)^{2}}{16 \lambda_{2}+8}-\frac{r\left\{(c+r-1)\left(\lambda_{1}+1\right)+\lambda_{2}[(c+1) r+c-1]\right\}\left\{(1-r)\left(\lambda_{1}+\lambda_{2}+1\right)+c\left[\left(-2 \lambda_{1}+\lambda_{2}\right) r+3 \lambda_{1}+\lambda_{2}+1\right]\right\}}{4\left(\lambda_{1}+\lambda_{2}+1\right)(1-r)^{2}\left[-1-(2-r) \lambda_{1}-(1+r) \lambda_{2}\right]}\right)^{+}$, the retail platform will open a self-operated channel.

\subsection{Manufacturer's consignment channel and retail platform's self-operated channel coexist}

When the manufacturer's consignment channel and retail platform's self-operated channel coexist in the market, the equilibrium wholesale price, retail price, demands in two channels, and profits of manufacturer and retail platform are shown as

$$
\begin{gathered}
\left\{\left[(11 c+2) \lambda_{2}+6 c+1\right] \lambda_{1}^{2}+\left[2(c+5) \lambda_{2}^{2}+3(4 c+5) \lambda_{2}+6 c+5\right] \lambda_{1}+4\left(2 \lambda_{2}^{3}+5 \lambda_{2}^{2}+4 \lambda_{2}+1\right)\right\} r^{2} \\
+4 c \lambda_{1}\left(1+\lambda_{2}\right)\left(1+\lambda_{1}+\lambda_{2}\right)+\left\{\left[-4(6 c+1) \lambda_{2}-2(7 c+1)\right] \lambda_{1}^{2}+\left[-2(11 c+6) \lambda_{2}^{2}\right.\right. \\
w_{3}^{*}=\frac{\left.\left.-18(2 c+1) \lambda_{2}-2(7 c+3)\right] \lambda_{1}-4\left(2 \lambda_{2}^{3}+5 \lambda_{2}^{2}+4 \lambda_{2}+1\right)\right\} r}{\left(\lambda_{1}+\lambda_{2}+1\right)\left\{\left[-16 \lambda_{2}^{2}+\left(17 \lambda_{1}-8\right) \lambda_{2}+9 \lambda_{1}\right] r^{2}+4\left[-4 \lambda_{2}^{2}-3\left(3 \lambda_{1}+2\right) \lambda_{2}-5 \lambda_{1}-2\right] r+4 \lambda_{1}\left(\lambda_{2}+1\right)\right\}} \\
p_{d 3}^{*}=\frac{\left\{\left[-2(5 c+4) \lambda_{2}-2(3 c+2)\right] \lambda_{1}-4\left(2 \lambda_{2}^{2}+3 \lambda_{2}+1\right)\right\} r+4 c \lambda_{1}\left(1+\lambda_{2}\right)}{\left[\left(17 \lambda_{2}+9\right) \lambda_{1}-16 \lambda_{2}^{2}-8 \lambda_{2}\right] r^{2}+\left[-4\left(9 \lambda_{2}+5\right) \lambda_{1}-8\left(2 \lambda_{2}^{2}+3 \lambda_{2}+1\right)\right] r+4 \lambda_{1}\left(\lambda_{2}+1\right)} \\
p_{r 3}^{*}=\frac{(r-2)\left\{[(5 r-2) c+4 r] \lambda_{2}-2 c+3 r\right\} \lambda_{1}^{2}-4 r\left(1+2 \lambda_{2}\right)\left(1+\lambda_{2}\right)^{2}}{\left(\lambda_{1}+\lambda_{2}+1\right)\left\{\left[-16 \lambda_{2}^{2}+\left(17 \lambda_{1}-8\right) \lambda_{2}+9 \lambda_{1}\right] r^{2}+4\left[-4 \lambda_{2}^{2}-3\left(3 \lambda_{1}+2\right) \lambda_{2}-5 \lambda_{1}-2\right] r+4 \lambda_{1}\left(\lambda_{2}+1\right)\right\}} \\
\\
\begin{array}{c}
\left\{\left[(7 c+9) \lambda_{2}+3 c+5\right] \lambda_{1}^{2}+\left[-\lambda_{2}^{2}+7(c+1) \lambda_{2}+3 c+4\right] \lambda_{1}-\left(1+\lambda_{2}\right)\left(1+2 \lambda_{2}\right)\left[1+(4 c+5) \lambda_{2}\right]\right\} r^{2} \\
+4 \lambda_{1}\left(1+\lambda_{2}\right)\left(1+\lambda_{1}+\lambda_{2}\right)(1-c)+\left\{\left[-4(3 c+5) \lambda_{2}-4(c+3)\right] \lambda_{1}^{2}+\left[-2(11 c+12) \lambda_{2}^{2}\right.\right.
\end{array} \\
\frac{\left.\left.-2(15 c+19) \lambda_{2}-2(4 c+7)\right] \lambda_{1}-2\left(1+\lambda_{2}\right)^{2}\left(1+2 \lambda_{2}\right)(1+2 c)\right\} r}{\left(\lambda_{1}+\lambda_{2}+1\right)\left\{\left[-16 \lambda_{2}^{2}+\left(17 \lambda_{1}-8\right) \lambda_{2}+9 \lambda_{1}\right] r^{2}+4\left[-4 \lambda_{2}^{2}-3\left(3 \lambda_{1}+2\right) \lambda_{2}-5 \lambda_{1}-2\right] r+4 \lambda_{1}\left(\lambda_{2}+1\right)\right\}} \\
D_{3}^{*}=\frac{\left(1+2 \lambda_{2}\right)\left[1+\lambda_{1}+\lambda_{2}+c\left(3 \lambda_{1}+4 \lambda_{2}\right)\right] r^{2}+\left(1+2 \lambda_{2}\right)\left[2\left(1+\lambda_{1}+\lambda_{2}\right)-2 c\left(3 \lambda_{1}+2 \lambda_{2}+2\right)\right] r}{\left[-16 \lambda_{2}^{2}+\left(17 \lambda_{1}-8\right) \lambda_{2}+9 \lambda_{1}\right] r^{2}+4\left[-4 \lambda_{2}^{2}-3\left(3 \lambda_{1}+2\right) \lambda_{2}-5 \lambda_{1}-2\right] r+4 \lambda_{1}\left(\lambda_{2}+1\right)}
\end{gathered}
$$




$$
\begin{aligned}
\pi_{m 3}^{*} & =\left[(1-r) p_{d}^{*}-c\right] D_{3}^{*}+\left(w^{*}-c\right) D_{4}^{*}-F \\
\pi_{r 3}^{*} & =r p_{d}^{*} D_{3}^{*}+\left(p_{r}^{*}-w^{*}\right) D_{4}^{*}+F .
\end{aligned}
$$

Compare the retail prices in two channels, if $\left[-16 \lambda_{2}^{2}+\left(17 \lambda_{1}-8\right) \lambda_{2}+9 \lambda_{1}\right] r^{2}+4\left[-4 \lambda_{2}^{2}-3\left(3 \lambda_{1}+2\right) \lambda_{2}-\left(5 \lambda_{1}+\right.\right.$ $2)] r+4 \lambda_{1}\left(\lambda_{2}+1\right)>0$ and $c<\left(\frac{\left(2-r\left(3+4 \lambda_{2}\right)\right)\left(1+\lambda_{1}+\lambda_{2}\right)}{\left[(5 r-2) \lambda_{1}+4(r+1)\right] \lambda_{2}+4\left(1+\lambda_{1}\right)}\right)^{+}$, the retail price in the manufacturer's consignment channel is higher than that in the retail platform's self-operated channel; otherwise, the retail price in the selfoperated channel is lower. If $\left[-16 \lambda_{2}^{2}+\left(17 \lambda_{1}-8\right) \lambda_{2}+9 \lambda_{1}\right] r^{2}+4\left[-4 \lambda_{2}^{2}-3\left(3 \lambda_{1}+2\right) \lambda_{2}-\left(5 \lambda_{1}+2\right)\right] r+4 \lambda_{1}\left(\lambda_{2}+1\right)<0$ and $c<\left(\frac{\left(2-r\left(3+4 \lambda_{2}\right)\right)\left(1+\lambda_{1}+\lambda_{2}\right)}{\left[(5 r-2) \lambda_{1}+4(r+1)\right] \lambda_{2}+4\left(1+\lambda_{1}\right)}\right)^{+}$, the retail price in the manufacturer's consignment channel is lower than that in the retail platform's self-operated channel; otherwise, the retail price in the self-operated channel is higher. When there are two distribution channels in the retail market, retail prices are usually different. Manufacturers and retail platforms have different experiences in the retail sector, which means they have different priorities for the factors that affect retail prices. Manufacturers need to pay attention to the production cost, consumers' concern on cost and revenue sharing ratio, while retail platforms pay more attention to consumers' perception of platform image and transaction satisfaction.

\section{Discussion AND MANAGERIAL INSIGHTS}

\subsection{Discussion}

Focusing on the manufacturer's consignment channel and retail platform's self-operated channel, this paper analyzes the influence of consumer's fairness concern and revenue sharing ratio on the decision-making and development strategies of manufacturer and retail platform under different channel modes. The main results in this paper are summarized below.

- When the retail market is a single-channel mode, retail prices are always negatively affected by concerns when production costs are low. When the retail market is in the mixed-channel mode, the retail price in the consignment channel always increases with concerns if the revenue sharing ratio is at a high level and is always positively affected by the revenue sharing ratio. The relative size of retail prices in both channels is correlated with concern level, revenue sharing ratio and production cost.

- If only the consignment channel exists, the profit changes of manufacturer and retail platform with respect to concerns are affected by the revenue sharing ratio and production cost, while the profit changes of manufacturer and retail platform with respect to revenue sharing ratio are associated with production cost. If only the self-operated channel exists, the wholesale price and manufacturer's profit have nothing to do with concerns, while the retail platform's profit is always negatively affected.

\subsection{Managerial insights}

In this section, we summarize key managerial insights into what the optimal development strategies of manufacturer and retail platform in different channel modes are. Specific managerial insights are listed below.

- Both the manufacturer and the retail platfrom should depend on consumers' fairness concerns to choose appreciate channel, i.e., the manufacture should wholesale all products when concerns and revenue sharing ratio are at low levels, while the retail platform should open a self-operated channel when concerns and revenue sharing ratio are at high levels. Therefore, the single-channel mode is also determined by the relative size of market power of the manufacturer and the retail platform.

- If the retail market channel mode has been formed, the retail platform should mitigate consumers' fairness concerns through prices cut when only the self-operated channel exists. When there are mixed channels in the market, the retail platform should keep consumers' fairness concerns and revenue sharing ratio at moderate levels, otherwise, it will suffer from profit loss. 


\subsection{Limitations}

Our research focuses on the impact of consumers' concerns on retail market, and the above conclusions provide relevant suggestions for the development of manufacturer and retail platform under different channel modes. Furthermore, retail market has more complex retail modes such as on-sale and pre-sale, etc., and the lag of product experience brought by online shopping will also lead to the uncertainty of consumer's product cognition. It will be interesting to study these more complex retail scenarios.

\section{Appendix A.}

\section{Proof of Proposition 4.1}

Substituting $D_{1}$ into equations (3.3) and (3.4). The retail price is only determined by the manufacturer. Let $\frac{\partial \pi_{m 1}}{\partial p_{d 1}}=0$, we can get the equilibrium retail price: $p_{d 1}^{*}=\frac{[(c+2) r-4 c-2] \lambda-c+r-1}{2(3 \lambda+1)(r-1)}$. Substituting the expression of $p_{d 1}^{*}$ into equations (3.3) and (3.4). Let $A=4(r-1)(3 \lambda+1)(2 \lambda+1)$, the equilibrium profits of manufacturer and retail platform can be obtained.

\section{Proof of Property 4.2}

(1) $\frac{\partial p_{d 1}^{*}}{\partial \lambda}=\frac{c-1}{2(3 \lambda+1)^{2}}$, if $0<c<1, \frac{\partial p_{d 1}^{*}}{\partial \lambda}<0$; otherwise, $\frac{\partial p_{d 1}^{*}}{\partial \lambda}>0$.

(2) $\frac{\partial p_{d 1}^{*}}{\partial r}=\frac{c}{2(r-1)^{2}}>0$.

(3) $\frac{\partial p_{d 1}^{*}}{\partial c}=\frac{(4-r) \lambda+1}{2(1-r)(3 \lambda+1)}>0$.

\section{Proof of Property 4.3}

(1) Let $\frac{\partial \pi_{m 1}^{*}}{\partial \lambda}=\frac{\left[-\left(15 c^{2}+16 c-4\right) r^{2}+\left(-6 c^{2}+32 c-8\right) r+12 c^{2}-16 c+4\right] \lambda^{2}+\left[\left(-6 c^{2}-16 c+4\right) r^{2}\right.}{\left.+\left(-12 c^{2}+32 c-8\right) r+12 c^{2}-16 c+4\right] \lambda-(r+c-1)[(4 c-1) r-3 c+1]}=0$. The solutions are:

$$
\begin{aligned}
& \bar{\lambda}_{1}=\frac{-3\left(r^{2}+2 r-2\right) c^{2}-8(r-1)^{2} c+2 r^{2}+2-4 r+(1-r) c \sqrt{r(3 r-2)(3 c-1)(c-1)}}{3\left(5 r^{2}+2 r-4\right) c^{2}+16(r-1)^{2} c-4(r-1)^{2}}<0, \\
& \bar{\lambda}_{2}=\frac{-3\left(r^{2}+2 r-2\right) c^{2}-8(r-1)^{2} c+2 r^{2}+2-4 r-(1-r) c \sqrt{r(3 r-2)(3 c-1)(c-1)}}{3\left(5 r^{2}+2 r-4\right) c^{2}+16(r-1)^{2} c-4(r-1)^{2}}
\end{aligned}
$$

Let $\bar{c}_{1}=\frac{r-1}{4 r-3}, \bar{c}_{2}=1-r$.

\begin{tabular}{|l|l|l|}
\hline Conditions & Solution of $\lambda$ & Changes of $\pi_{m 1}^{*}$ with respect to $\lambda$ \\
\hline \multirow{3}{*}{$0<r<0.5$ or $0.75<r<1$} & $0<c<\bar{c}_{1}$ or $c>\bar{c}_{2}$ & $\frac{\partial \pi_{m 1}^{*}}{\partial \lambda}>0$ \\
\cline { 2 - 3 } & $\bar{c}_{1}<c<\bar{c}_{2}$ & $0<\lambda<\lambda_{2}, \quad \frac{\partial \pi_{m 1}^{*}}{\partial \lambda}<0 ; \lambda_{2}<\lambda<1 \frac{\partial \pi_{m 1}^{*}}{\partial \lambda}>0$ \\
\hline \multirow{2}{*}{$0.5<r<0.75$} & $0<c<\bar{c}_{2}$ or $c>\bar{c}_{1}$ & $\frac{\partial \pi_{m 1}^{*}}{\partial \lambda}>0$ \\
\cline { 2 - 3 } & $\bar{c}_{2}<c<\bar{c}_{1}$ & $0<\lambda<\lambda_{2}, \quad \frac{\partial \pi_{m 1}^{*}}{\partial \lambda}<0 ; \lambda_{2}<\lambda<1 \frac{\partial \pi_{m 1}^{*}}{\partial \lambda}>0$ \\
\hline
\end{tabular}

(2) Let $\frac{\partial \pi_{m 1}^{*}}{\partial r}=\frac{\left[-\left(3 c^{2}+8 c+4\right) r^{2}+2(3 c+2)(c+2) r+6 c^{2}-8 c-4\right] \lambda^{2}}{+\left[-4(c+1) r^{2}+8(c+1) r+6 c^{2}-4 c-4\right] \lambda+c^{2}-r^{2}+2 r-1}=0$. The solutions are

$$
\bar{c}_{3}=\frac{(2 \lambda+1)(1-r)\left[2 \lambda(1-r)+\sqrt{\lambda^{2} r(r-2)+10 \lambda^{2}+6 \lambda+1}\right]}{6 \lambda^{2}+6 \lambda+1-3 \lambda^{2} r(r-2)}>0,
$$




$$
\bar{c}_{4}=\frac{(2 \lambda+1)(r-1)\left[2 \lambda(r-1)+\sqrt{\lambda^{2} r(r-2)+10 \lambda^{2}+6 \lambda+1}\right]}{3 \lambda^{2} r(2-r)+6 \lambda^{2}+6 \lambda+1}<0 .
$$

Let $B=\left[-2(3 c+4) r^{2}+4(3 c+4) r+12 c-8\right] \lambda^{2}-4\left(r^{2}-3 c-2 r+1\right) \lambda+2 c$

(i) If $B>0$, when $0<c<\bar{c}_{3}, \frac{\partial \pi_{m 1}^{*}}{\partial r}<0 ; c>\bar{c}_{3}, \frac{\partial \pi_{m 1}^{*}}{\partial r}>0$.

(ii) If $B<0$, when $0<c<\bar{c}_{3}, \frac{\partial \pi_{m 1}^{*}}{\partial r}>0 ; c>\bar{c}_{3}, \frac{\partial \pi_{m 1}^{*}}{\partial r}<0$.

(3) As $\frac{\partial \pi_{m 1}^{*}}{\partial c}=\frac{-2\left(3 \lambda^{2} r^{2}+6 c \lambda^{2} r+4 \lambda r+2 \lambda+1\right) c+2(1-r)(2 \lambda+1)(2 \lambda r+\lambda+1)}{A}, \frac{\partial \pi_{m 1}^{*}}{\partial c}<0$ when $c<\frac{(1-r)(2 \lambda+1)(2 \lambda r+\lambda+1)}{3 \lambda^{2} r^{2}+6 \lambda^{2} r+4 \lambda r+2 \lambda+1}$; $\frac{\partial \pi_{m 1}^{*}}{\partial c}>0$ when $c>\frac{(1-r)(2 \lambda+1)(2 \lambda r+\lambda+1)}{3 \lambda^{2} r^{2}+6 \lambda^{2} r+4 \lambda r+2 \lambda+1}$.

(4) $\frac{\partial \pi_{m 1}^{*}}{\partial F}=-1$.

\section{Proof of Property 4.4}

(1) $\frac{\partial \pi_{r 1}^{*}}{\partial \lambda}=\frac{r\left\{\begin{array}{l}{\left[\left(15 c^{2}+16 c-4\right) r^{2}+8\left(-6 c^{2}-4 c+1\right) r+24 c^{2}+16 c-4\right] \lambda^{2}+(4 c-1) r^{2}+2\left(-c^{2}-4 c+1\right) r+c^{2}+4 c-1} \\ +\left[\left(6 c^{2}+16 c-4\right) r^{2}+8\left(-3 c^{2}-4 c+1\right) r+12 c^{2}+16 c-4\right] \lambda\end{array}\right.}{A(3 \lambda+1)(r-1)(2 \lambda+1)}$.

Let $C=3\left(5 r^{2}-16 r+8\right) \lambda^{2}+6\left(r^{2}-4 r+2\right) \lambda-2 r+1$. When $\frac{\partial \pi_{r 1}^{*}}{\partial \lambda}=0$, we can know the solutions:

$$
\begin{aligned}
\bar{c}_{5} & =\frac{(2 \lambda+1)(1-r)\left[(4 \lambda+2)(r-1)-\sqrt{\left(31 r^{2}-80 r+40\right) \lambda^{2}+2\left(11 r^{2}-28 r+14\right) \lambda+4 r^{2}-10 r+5}\right]}{C}, \\
\bar{c}_{6} & =\frac{(2 \lambda+1)(1-r)\left[(4 \lambda+2)(r-1)+\sqrt{\left(31 r^{2}-80 r+40\right) \lambda^{2}+2\left(11 r^{2}-28 r+14\right) \lambda+4 r^{2}-10 r+5}\right]}{C} \\
& >0 .
\end{aligned}
$$

\begin{tabular}{|l|l|l|l|}
\hline \multicolumn{2}{|c|}{ Conditions } & Changes of $\pi_{r 1}^{*}$ with respect to $\lambda$ \\
\hline$C>0$ & - & $\bar{c}_{5}<0<\bar{c}_{6}$ & $0<c<\bar{c}_{6}, \frac{\partial \pi_{r 1}^{*}}{\partial \lambda}<0 ; c>\bar{c}_{6}, \frac{\partial \pi_{r 1}^{*}}{\partial \lambda}>0$ \\
\hline$C<0$ & $c>-\frac{2(2 \lambda+1)^{2}(r-1)^{2}}{C}$ & $0<\bar{c}_{6}<\bar{c}_{5}$ & $\begin{array}{l}0<c<\bar{c}_{6}, \frac{\partial \pi_{r 1}^{*}}{\partial \lambda}<0 ; \bar{c}_{6}<c<\bar{c}_{5}, \frac{\partial \pi_{r 1}^{*}}{\partial \lambda}>0 ; \\
c>\bar{c}_{5}, \frac{\partial \pi_{r 1}^{*}}{\partial \lambda}<0\end{array}$ \\
\cline { 2 - 5 } & $c<-\frac{2(2 \lambda+1)^{2}(r-1)^{2}}{C}$ & $0<\bar{c}_{6}<\bar{c}_{5}$ & $\begin{array}{l}0<c<\bar{c}_{6}, \frac{\partial \pi_{r 1}^{*}}{\partial \lambda}>0 ; \bar{c}_{6}<c<\bar{c}_{5}, \frac{\partial \pi_{r 1}^{*}}{\partial \lambda}<0 ; \\
c>\bar{c}_{5}, \frac{\partial \pi_{r 1}^{*}}{\partial \lambda}>0\end{array}$ \\
\hline
\end{tabular}

(2) $\frac{\partial \pi_{r 1}^{*}}{\partial r}=\frac{+\left[4(c+1) r^{3}-12(c+1) r^{2}+4\left(2 c^{2}+3 c+3\right) r+4 c^{2}-4 c-4\right] \lambda+r c^{2}+r^{3}+c^{2}-3 r^{2}+3 r-1}{(r-1)^{2} A}$, when $\frac{\partial \pi_{r 1}^{*}}{\partial r}=0, \bar{c}_{7}=\frac{(r-1)(2 \lambda+1)\left[\sqrt{(r-1)[1+(r+2) \lambda]\left[\left(r^{2}-5 r-2\right) \lambda-r-1\right]}-2 \lambda(r-1)^{2}\right]}{3\left(r^{3}-3 r^{2}+8 r\right) \lambda^{2}+4(2 r+1) \lambda+r+1}<0$, $\bar{c}_{8}=\frac{(1-r)(2 \lambda+1)\left[\sqrt{(r-1)[1+(r+2) \lambda]\left[\left(r^{2}-5 r-2\right) \lambda-r-1\right]}+2 \lambda(r-1)^{2}\right]}{3\left(r^{3}-3 r^{2}+8 r\right) \lambda^{2}+4(2 r+1) \lambda+r+1}>0$.

Let $\bar{c}_{9}=\frac{2 \lambda(2 \lambda+1)\left(1-r^{3}\right)}{3\left(r^{3}-3 r^{2}+8 r\right) \lambda^{2}+4(2 r+1) \lambda+r+1}, 0<\bar{c}_{9}<\bar{c}_{8}$.

When $0<c<\bar{c}_{9}, \frac{\partial \pi_{r 1}^{*}}{\partial r}<0$; when $\bar{c}_{9}<c<\bar{c}_{8}, \frac{\partial \pi_{r 1}^{*}}{\partial r}>0$; when $c>\bar{c}_{8}, \frac{\partial \pi_{r 1}^{*}}{\partial r}<0$.

(3) As $\frac{\partial \pi_{r 1}^{*}}{\partial r}=\frac{2 r\left[3 r(r-4) \lambda^{2}-2(r+2) \lambda-1\right] c+8 r \lambda^{2}(1-r)^{2}+4 r \lambda(1-r)}{A(r-1)}, \frac{\partial \pi_{r 1}^{*}}{\partial r}>0$ when $c<\frac{2 \lambda(1-r)^{2}(2 \lambda+1)}{(3 \lambda r+1)[(4-r) \lambda-1]} ; \frac{\partial \pi_{r 1}^{*}}{\partial r}<0$ when $c<\frac{2 \lambda(1-r)^{2}(2 \lambda+1)}{(3 \lambda r+1)[(4-r) \lambda-1]}$

(4) $\frac{\partial \pi_{r 1}^{*}}{\partial F}=1$. 


\section{Proof of Proposition 4.5}

Substituting $D_{2}$ into equations (3.5) and (3.6), let $p_{r 2}=w_{2}+m_{2}$. In this case, the retail price is determined by the retail platform, while the wholesale price is determined by manufacturer. By backward induction, the equilibrium wholesale price is first solved, thus let $\frac{\partial \pi_{m 2}}{\partial w_{2}}=0$, we can get $w_{2}^{*}=\frac{(c-2 m+1) \lambda+c-m+1}{2(\lambda+1)}$.

Substituting $w_{2}^{*}$ into equation (3.6) to solve the equilibrium retail price. Let $\frac{\partial \pi_{r 2}}{\partial m_{2}}=0$, we can get the equilibrium marginal profit: $m_{2}^{*}=\frac{(\lambda+1)(1-c)}{4 \lambda+2}$. Substituting $m_{2}^{*}$ into $w_{2}^{*}$ and simplifying to obtain the equilibrium wholesale price: $w_{2}^{*}=\frac{3 c+1}{4}$. Let $p_{r 2}^{*}=w_{2}^{*}+m_{2}^{*}$, we can get the equilibrium retail price: $p_{r 2}^{*}=\frac{4 \lambda(c+1)+c+3}{8 \lambda+4}$. Substituting $w_{2}^{*}, p_{r 2}^{*}$ into equations (3.5) and (3.6), then the equilibrium profit of manufacturer and retail platform can be obtained: $\pi_{m 2}^{*}=\frac{(c-1)^{2}}{16}, \pi_{r 2}^{*}=\frac{(\lambda+1)(c-1)^{2}}{16 \lambda+8}$.

\section{Proof of Property 4.6}

(1) (1) $\frac{\partial w_{2}^{*}}{\partial \lambda}=0$; (2) $\frac{\partial p_{r 2}^{*}}{\partial \lambda}=\frac{c-1}{2(2 \lambda+1)^{2}}$, if $0<c<1$, $\frac{\partial p_{r 2}^{*}}{\partial \lambda}<0$, otherwise, $\frac{\partial p_{r 2}^{*}}{\partial \lambda}>0$;

(2) $\frac{\partial \pi_{m 2}^{*}}{\partial \lambda}=0 ; \frac{\partial \pi_{r 2}^{*}}{\partial \lambda}=-\frac{(c-1)^{2}}{8(2 \lambda+1)^{2}}<0$.

\section{Proof of Lemma 4.7}

(1) Let $\pi_{m 1}^{*}-\pi_{m 2}^{*}=0$, we can get:

$$
F=\bar{F}_{1}=\frac{\begin{array}{l}
{\left[-4(3 c+2)(c+2) r^{2}+2\left(-15 c^{2}+14 c+13\right) r+6 c^{2}+4 c-10\right] \lambda^{2}} \\
+\left[-16(c+1) r^{2}+\left(-21 c^{2}+2 c+27\right) r-3 c^{2}+14 c-11\right] \lambda-4 r^{2}-(c+7)(c-1) r-3(c-1)^{2}
\end{array}}{4 A} .
$$

When $F<\bar{F}_{1}, \pi_{m 1}^{*}>\pi_{m 2}^{*}$; when $F>\bar{F}_{1}, \pi_{m 1}^{*}<\pi_{m 2}^{*}$.

(2) Let $\pi_{r 1}^{*}-\pi_{r 2}^{*}=0$, we can get:

$$
F=\bar{F}_{2}=\frac{\left[-2(c+2)^{2} r^{3}+\left(7 c^{2}+10 c+19\right) r^{2}+2\left(5 c^{2}+2 c-7\right) r+3(c-1)^{2}\right] \lambda^{2}+\left[-4(c+2) r^{3}\right.}{\left.+4\left(c^{2}+5\right) r^{2}+4(c+4)(c-1) r+4(c-1)^{2}\right] \lambda-2 r^{3}+\left(c^{2}-2 c+5\right) r^{2}+4(c-1) r+(c-1)^{2}} .
$$

When $F<\bar{F}_{2}, \pi_{r 1}^{*}<\pi_{r 2}^{*}$; when $F>\bar{F}_{2}, \pi_{r 1}^{*}>\pi_{r 2}^{*}$.

\section{Proof of Proposition $\mathbf{4 . 8}$}

The KKT (Karush-Kuhn-Tucker) condition is used to obtain the optimal solution with inequality constraints. Substituting $D_{3}=1-v_{d r}, \quad D_{4}=v_{d r}-v_{r}$ into equations (3.7) and (3.8). Let $p_{r 3}=w_{3}+m_{3}$ and $m_{3}$ is marginal profit.

(1) Function construction

(1) Manufacturer's profit

$$
\left\{\begin{array}{l}
\max \pi_{m 3}=\max \left\{\left[(1-r) p_{d}-c\right] D_{3}+(w-c) D_{4}-F\right\} \\
\text { s.t. } \quad \frac{\left(c-2 w+4 p_{r}\right) \lambda^{2}+\left(c-w+4 p_{r}\right) \lambda+p_{r}}{(3 \lambda+1)(\lambda+1)} \leq p_{d 3}
\end{array}\right.
$$

Construct the Lagrange function, $L_{1}=\pi_{m 3}+\chi_{1}\left\{p_{d 3}-\frac{\left(c-2 w+4 p_{r}\right) \lambda^{2}+\left(c-w+4 p_{r}\right) \lambda+p_{r}}{(3 \lambda+1)(\lambda+1)}\right\}$.

(a) When $\chi_{1} \neq 0$, KKT conditions are $\left\{\begin{array}{l}\frac{\partial L_{1}}{\partial p_{d 3}}=0 \\ \frac{\partial L_{1}}{\partial w_{3}}=0 \\ \frac{\partial L_{1}}{\partial \chi_{1}} \geq 0 \\ \chi_{1}>0\end{array}\right.$; 
(b) When $\chi_{1}=0, L_{1}=\pi_{m 3}$.

(2) Retail platform's profit

$$
\left\{\begin{array}{l}
\max \pi_{r 3}=\max \left[r p_{d} D_{3}+\left(p_{r}-w\right) D_{4}+F\right] \\
\text { s.t. } \quad \frac{\left(c-2 w+4 p_{r}\right) \lambda^{2}+\left(c-w+4 p_{r}\right) \lambda+p_{r}}{(3 \lambda+1)(\lambda+1)} \leq p_{d 3} .
\end{array}\right.
$$

Construct the Lagrange function, $L_{2}=\pi_{r 3}+\chi_{2}\left\{p_{d 3}-\frac{\left(c-2 w+4 p_{r}\right) \lambda^{2}+\left(c-w+4 p_{r}\right) \lambda+p_{r}}{(3 \lambda+1)(\lambda+1)}\right\}$.

(a) When $\chi_{2} \neq 0$, KKT conditions are $\left\{\begin{array}{l}\frac{\partial L_{2}}{\partial m_{3}}=0 \\ \frac{\partial L_{2}}{\partial \chi_{2}} \geq 0 \\ \chi_{2}>0\end{array}\right.$;

(b) When $\chi_{2}=0, L_{1}=\pi_{r 3}$.

(2) Equilibrium solution

(1) When $\chi_{i} \neq 0$, the assumptions of the model are not met, and there is no equilibrium solution for $p_{r 3}$, this situation is discarded.

(2) When $\chi_{i}=0$, it is proved that the Hessian matrix of $\pi_{m 3}$ and $\pi_{r 3}$ about $p_{d 3}, p_{r 3}$ and $w_{3}$ exists, so it is solved by backward induction. Firstly, the expression of equilibrium wholesale price can be obtained from $\frac{\partial \pi_{m 3}}{\partial w}=0$.

$$
w_{3}^{*}=\frac{\left[(4-r) p_{d}-4 m\right] \lambda^{2}+\left[(6-2 r) p_{d}-4 m\right] \lambda+(2-r) p_{d}-m}{2(2 \lambda+1)(\lambda+1)} .
$$

Substituting $w_{3}^{*}$ into equations (3.7) and (3.8), and let $\frac{\partial \pi_{m 3}}{\partial p_{d 3}}=0, \frac{\partial \pi_{r 3}}{\partial m_{3}}=0$. Let $D=(\lambda+1) r^{2}-(24 \lambda+10) r+$ $20 \lambda+8$, the equilibrium solution can be obtained by solving simultaneously:

$$
\begin{aligned}
p_{d 3}^{*} & =\frac{-2 r[(5 c+4) \lambda+c+2]+8(2 c+1) \lambda+4(c+1)}{D} \\
m_{3}^{*} & =-\frac{(\lambda+1)\left\{\begin{array}{l}
{\left[(17 c+12) r^{2}-2(31 c+2) r+24 c-8\right] \lambda^{2}+\left[(15 c+14) r^{2}-10(4 c+1) r+12 c-4\right] \lambda} \\
+2 r[(c+2) r-2 c-2]
\end{array}\right\}}{(2 \lambda+1)^{2} D} .
\end{aligned}
$$

Substituting $p_{d 3}^{*}$ and $m_{3}^{*}$ into the expression for $w_{3}^{*}$, then the equilibrium retail price can be obtained: $w_{3}^{*}=\frac{(r-1)\left\{[(13 c+10) r-34 c-12] \lambda^{2}+[13(c+1) r-26 c-14] \lambda+2(c+2) r-4 c-4\right\}}{(2 \lambda+1) D}$.

Let $p_{r 3}^{*}=w_{3}^{*}+m_{3}^{*}$, the equilibrium retail price of self-operated channel can be obtained:

$$
p_{r 3}^{*}=\frac{\left[(9 c+8) r^{2}-8(4 c+5) r+4(11 c+8)\right] \lambda^{3}+\left[(7 c+10) r^{2}-(23 c+62) r+50 c+52\right] \lambda^{2}}{(2 \lambda+1)^{2} D} .
$$

Substituting $p_{d 3}^{*}, p_{r 3}^{*}$ and $w_{3}^{*}$ into equations (3.7) and (3.8), and let

$$
\begin{aligned}
a_{1}= & 2\left(11 c^{2}-F+21 c+10\right) \lambda^{3}+\left(20 c^{2}-5 F+57 c+36\right) \lambda^{2}+\left(2 c^{2}-4 F+20 c+21\right) \lambda-F+c+4, \\
a_{2}= & 2\left(-77 c^{2}+48 F-204 c-124\right) \lambda^{3}+2\left(-19 c^{2}+92 F-192 c-188\right) \lambda^{2}+2\left(11 c^{2}+54 F-39 c-95\right) \lambda \\
& +2 c^{2}+20 F+6 c-32, \\
a_{3}= & \left(-43 c^{2}-1232 F+396 c+580\right) \lambda^{3}-2\left(93 c^{2}+844 F-69 c-426\right) \lambda^{2}-\left(67 c^{2}+768 F+142 c-417\right) \lambda+4 c^{2} \\
& -116 F-56 c+68, \\
a_{4}= & 4\left(19 c^{2}+480 F+24 c-124\right) \lambda^{3}+8\left(-11 c^{2}+316 F+70 c-90\right) \lambda^{2}+4\left(-21 c^{2}+276 F+97 c-87\right) \lambda-24 c^{2} \\
& +160 F+80 c-56, \\
a_{5}= & 4\left(9 c^{2}-200 F-36 c+36\right) \lambda^{3}+8\left(11 c^{2}-130 F-35 c+26\right) \lambda^{2}+4\left(17 c^{2}-112 F-42 c+25\right) \lambda \\
& +16 c^{2}-64 F-32 c+16 .
\end{aligned}
$$




$$
\begin{aligned}
b_{1}= & -2\left(17 c^{2}-2 F+29 c+12\right) r^{4}+\left(493 c^{2}-192 F+894 c+368\right) r^{3}+4\left(-95 c^{2}+616 F-373 c-134\right) r^{2} \\
& -4\left(97 c^{2}+960 F-174 c-40\right) r+48 c^{2}+1600 F-112 c+32, \\
b_{2}= & -\left(64 c^{2}-12 F+133 c+64\right) r^{4}+\left(551 c^{2}-464 F+1471 c+752\right) r^{3}-2\left(31 c^{2}-2304 F+1227 c+536\right) r^{2} \\
& -2\left(454 c^{2}+3488 F-614 c-160\right) r+120 c^{2}+2880 F-232 c+64, \\
b_{3}= & -\left(34 c^{2}-13 F+102 c+62\right) r^{4}+\left(143 c^{2}-400 F+850 c+588\right) r^{3}+2\left(160 c^{2}+1612 F-695 c-415\right) r^{2} \\
& -4\left(179 c^{2}+1184 F-180 c-66\right) r+96 c^{2}+1936 F-152 c+40, \\
b_{4}= & -\left(4 c^{2}-6 F+29 c+26\right) r^{4}-\left(15 c^{2}+148 F-185 c-208\right) r^{3}+2\left(81 c^{2}+500 F-142 c-147\right) r^{2} \\
& -4\left(53 c^{2}+356 F-35 c-26\right) r+24 c^{2}+576 F-32 c+8, \\
b_{5}= & (F-2 c-4) r^{4}-4\left(c^{2}+5 F-2 c-7\right) r^{3}+4\left(4 c^{2}+29 F-2 c-10\right) r^{2}-16\left(c^{2}+10 F-1\right) r+64 F .
\end{aligned}
$$

The equilibrium profits of manufacturer and retail platform can be obtained:

$$
\begin{aligned}
\pi_{m 3}^{*} & =\frac{a_{1} r^{4}+a_{2} r^{3}+a_{3} r^{2}+a_{4} r+a_{5}}{(2 \lambda+1) D^{2}} \\
\pi_{r 3}^{*} & =\frac{b_{1} \lambda^{4}+b_{2} \lambda^{3}+b_{3} \lambda^{2}+b_{4} \lambda+b_{5}}{(2 \lambda+1)^{2} D^{2}} .
\end{aligned}
$$

\section{Proof of Lemma 4.9}

Let $\Delta p^{*}=p_{d 3}^{*}-p_{r 3}^{*}=-\frac{\lambda\left\{\begin{array}{l}{\left[(9 c+8) r^{2}+8(c-1) r-20 c\right] \lambda^{2}+\left[(7 c+10) r^{2}+(25 c-14) r-30 c+4\right] \lambda} \\ +3 r^{2}+(11 c-5) r-10 c+2\end{array}\right\}}{(2 \lambda+1)^{2} D}=0, \bar{c}_{10}=$ $\frac{(2 \lambda+1)(1-r)(4 \lambda r+3 r-2)}{20} \lambda^{2}+\left(7 r^{2}+25 r-30\right) \lambda+11 r-10$. Let $E=\left(9 r^{2}+8 r-20\right) \lambda^{2}+\left(7 r^{2}+25 r-30\right) \lambda+11 r-10$.

(1) When $\frac{E}{D}<0$, if $c<\bar{c}_{10}, \Delta p^{*}<0, p_{d 3}^{*}<p_{r 3}^{*}$; if $c>\bar{c}_{10}, \Delta p^{*}>0, p_{d 3}^{*}>p_{r 3}^{*}$.

(2) When $\frac{E}{D}>0$, if $c<\bar{c}_{10}, \Delta p^{*}>0, p_{d 3}^{*}>p_{r 3}^{*}$; if $c>\bar{c}_{10}, \Delta p^{*}<0, p_{d 3}^{*}<p_{r 3}^{*}$.

\section{Proof of Property 4.10}

(1) $\frac{\partial p_{d 3}^{*}}{\partial \lambda}=\frac{4(1-r)\left[(2 c+1) r^{2}+2(2-7 c) r+4(3 c-1)\right]}{D^{2}}$.

(1) When $0<r<2 \sqrt{2}-2$, if $c>\frac{-r^{2}-4 r+4}{2 r^{2}-14 r+12}$, $\frac{\partial p_{d 3}^{*}}{\partial \lambda}>0$; if $0<c<\frac{-r^{2}-4 r+4}{2 r^{2}-14 r+12}, \frac{\partial p_{d 3}^{*}}{\partial \lambda}<0$.

(2) When $2 \sqrt{2}-2<r<1, \frac{\partial p_{d 3}^{*}}{\partial \lambda}>0$.

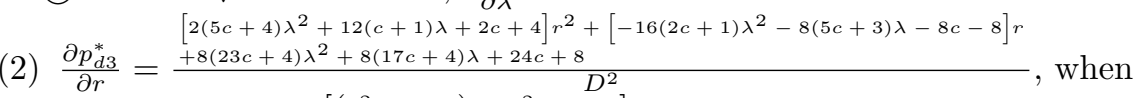

$c>\bar{c}_{11}=\frac{-2\left[\left(r^{2}-2 r+4\right) \lambda+r^{2}-2 r+2\right](1+2 \lambda)}{\left(5 r^{2}-16 r+92\right) \lambda^{2}+2\left(3 r^{2}-10 r+34\right) \lambda+r^{2}-4 r+12}, \frac{\partial p_{d 3}^{*}}{\partial r}>0$. Because of $\bar{c}_{11}<0, \frac{\partial p_{d 3}^{*}}{\partial r}>0$ always holds.

$\frac{\partial p_{d 3}^{*}}{\partial c}=\frac{-2 r(5 \lambda+1)+4(4 \lambda+1)}{D}$ and $\frac{\partial p_{d 3}^{*}}{\partial c \partial \lambda}=\frac{8(6-r)(1-r)^{2}}{D^{2}}>0$. Solve $\frac{\partial p_{d 3}^{*}}{\partial c}=\frac{-2 r(5 \lambda+1)+4(4 \lambda+1)}{D}$, we get $\lambda=\frac{2-r}{-8+5 r}<$

0 , so that $\frac{\partial p_{d 3}^{*}}{\partial c}=\frac{-2 r(5 \lambda+1)+4(4 \lambda+1)}{D}>0$ for $\lambda \in(0,1)$.

$$
c\left[2\left(22 r^{4}-154 r^{3}-43 r^{2}+76 r+36\right) \lambda^{3}+4\left(10 r^{4}-19 r^{3}-93 r^{2}+28 r+44\right) \lambda^{2}\right.
$$

$\left.+2\left(r^{4}+22 r^{3}-67 r^{2}-44 r+68\right) \lambda+4\left(r^{3}+2 r^{2}-12 r+8\right)\right]+(2 \lambda+1)\left[\left(21 \lambda^{2}+18 \lambda+1\right) r^{4}\right.$

(3) (1) $\frac{\partial \pi_{m 3}^{*}}{\partial c}=\frac{\left.-6\left(34 \lambda^{2}+15 \lambda-1\right) r^{3}+2\left(99 \lambda^{2}-15 \lambda-28\right) r^{2}+8\left(6 \lambda^{2}+25 \lambda+10\right) r-8\left(9 \lambda^{2}+13 \lambda+4\right)\right]}{(2 \lambda+1) D^{2}}$, and $\frac{\partial \pi_{m 3}^{*}}{\partial c^{2}}=\frac{G}{(2 \lambda+1) D^{2}}$, so that, if $G>0$, the manufacturer's profit is firstly decreasing and then increasing in the production cost; if $G<0$, the manufacturer's profit is firstly increasing and then decreasing in the production cost.

$$
\begin{aligned}
& c\left[2\left(-34 r^{4}+493 r^{3}-380 r^{2}-388 r+48\right) \lambda^{4}+2\left(-64 r^{4}+551 r^{3}-62 r^{2}-908 r+120\right) \lambda^{3}\right. \\
& +2\left(-34 r^{4}+143 r^{3}+320 r^{2}-716 r+96\right) \lambda^{2}+2\left(-4 r^{4}-15 r^{3}+162 r^{2}-212 r+24\right) \lambda
\end{aligned}
$$

(2) $\frac{\partial \pi_{r 3}^{*}}{\partial c}=\frac{+2\left(373 \lambda^{3}+427 \lambda^{2}+134 \lambda+4\right) r^{2}-4\left(87 \lambda^{3}+110 \lambda^{2}+35\right) r+8\left(7 \lambda^{3}+11 \lambda^{2}+4 \lambda\right)}{(2 \lambda+1) D^{2}}$, and $\frac{\partial \pi_{r 3}^{*}}{\partial c^{2}}=\frac{H}{(2 \lambda+1) D^{2}}$, so that, if $H>0$, the retail platform's profit is firstly decreasing and then increasing in the production cost; if $H<0$, the retail platform's profit is firstly increasing and then decreasing in the production cost.

(4) $\frac{\partial \pi_{m 3}^{*}}{\partial F}=-1$, and $\frac{\partial \pi_{r 3}^{*}}{\partial F}=1$. 


\section{Model extension}

Only manufacturer's consignment channel exists.

When $c<\left(\frac{1+\lambda_{2}-r\left(1+2 \lambda_{2}\right)}{1+(r+1) \lambda_{2}}\right)^{+}, \frac{\partial p_{d 1}^{*}}{\partial \lambda_{1}}<0$; when $c>\left(\frac{1+\lambda_{2}-r\left(1+2 \lambda_{2}\right)}{1+(r+1) \lambda_{2}}\right)^{+}, \frac{\partial p_{d 1}^{*}}{\partial \lambda_{1}}>0$.

When $c<\left(\frac{\lambda_{1}-r\left(2 \lambda_{1}+1\right)}{(r+1) \lambda_{1}}\right)^{+}, \frac{\partial p_{d 1}^{*}}{\partial \lambda_{2}}>0$; when $c>\left(\frac{\lambda_{1}-r\left(2 \lambda_{1}+1\right)}{(r+1) \lambda_{1}}\right)^{+}, \frac{\partial p_{d 1}^{*}}{\partial \lambda_{2}}<0$.

Let

$$
\begin{aligned}
& \lambda_{1 L}=\min \left\{\begin{array}{l}
{[1-r-c(r+1)] \lambda_{2}-c-r-1} \\
c+r-1
\end{array}, \frac{\begin{array}{l}
{\left[-2 r^{2}+(c+3) r+c-1\right] \lambda_{2}^{2}+\left[-(c+3) r^{2}+5 r+2 c-2\right] \lambda_{2}} \\
+(1-r)(c+r-1)
\end{array}}{\left[2(c+1) r^{2}-(2 c+3) r-c+1\right] \lambda_{2}+(r-1)(c+r-1)}\right\}, \\
& \lambda_{1 H}=\max \left\{\frac{[1-r-c(r+1)] \lambda_{2}-c-r-1}{c+r-1}, \frac{\begin{array}{l}
{\left[-2 r^{2}+(c+3) r+c-1\right] \lambda_{2}^{2}+\left[-(c+3) r^{2}+5 r+2 c-2\right] \lambda_{2}} \\
{\left[2(c+1) r^{2}-(2 c+3) r-c+1\right] \lambda_{2}+(r-1)(c+r-1)}
\end{array}}{[2+r+r-1)}\right.
\end{aligned}
$$

(1) When $(1-r-c)\left\{\left[1+2(c+1) \lambda_{2}\right] r^{2}+\left[c-2-(2 c+3) \lambda_{2}\right] r-\left(\lambda_{2}+1\right)(c-1)\right\}>0, \frac{\partial \pi_{m 1}^{*}}{\partial \lambda_{1}}>0$ if $\lambda_{1 H}>0$ and $\lambda_{1 L}{ }^{+}<\lambda_{1}<\lambda_{1 H}$; otherwise, $\frac{\partial \pi_{m 1}^{*}}{\partial \lambda_{1}}<0$.

(2) When $(1-r-c)\left\{\left[1+2(c+1) \lambda_{2}\right] r^{2}+\left[c-2-(2 c+3) \lambda_{2}\right] r-\left(\lambda_{2}+1\right)(c-1)\right\}<0, \frac{\partial \pi_{m 1}^{*}}{\partial \lambda_{1}}<0$ if $\lambda_{1 H}>0$ and $\lambda_{1 L}{ }^{+}<\lambda_{1}<\lambda_{1 H}$; otherwise, $\frac{\partial \pi_{m 1}^{*}}{\partial \lambda_{1}}>0$.

Let $\quad \lambda_{2 L}=\min \left\{\frac{-\left(\lambda_{1}+1\right)(c+r-1)}{(r+1) c-1+r}, \frac{\left(\lambda_{1}+1\right)\left\{\left[1+2(c+1) \lambda_{1}\right] r^{2}-\left[(2 c+3) \lambda_{1}+c+1\right] r-\lambda_{1}(c-1)\right\}}{\left(c-2 \lambda_{1}-1\right) r^{2}+\left[(c+3) \lambda_{1}+c+1\right] r+\lambda_{1}(c-1)}\right\}, \quad \lambda_{2 H}=$ $\max \left\{\frac{-\left(\lambda_{1}+1\right)(c+r-1)}{(r+1) c-1+r}, \frac{\left(\lambda_{1}+1\right)\left\{\left[1+2(c+1) \lambda_{1}\right] r^{2}-\left[(2 c+3) \lambda_{1}+c+1\right] r-\lambda_{1}(c-1)\right\}}{\left(c-2 \lambda_{1}-1\right) r^{2}+\left[(c+3) \lambda_{1}+c+1\right] r+\lambda_{1}(c-1)}\right\}$. When $[(c+1) r+c-1]\left\{\left(-c+2 \lambda_{1}+\right.\right.$ 1) $\left.r^{2}-\left[(c+3) \lambda_{1}+c+1\right] r-\lambda_{1}(c-1)\right\}>0, \frac{\partial \pi_{m 1}^{*}}{\partial \lambda_{2}}>0$ if $\lambda_{2 H}>0$ and $\lambda_{2 L}{ }^{+}<\lambda_{2}<\lambda_{2 H}$; otherwise, $\frac{\partial \pi_{m 1}^{*}}{\partial \lambda_{2}}<0$. When $[(c+1) r+c-1]\left\{\left(-c+2 \lambda_{1}+1\right) r^{2}-\left[(c+3) \lambda_{1}+c+1\right] r-\lambda_{1}(c-1)\right\}<0, \frac{\partial \pi_{m 1}^{*}}{\partial \lambda_{2}}<0$ if $\lambda_{2 H}<0$ and $\lambda_{2 L}{ }^{+}<\lambda_{2}<\lambda_{2 H}$; otherwise, $\frac{\partial \pi_{m 1}^{*}}{\partial \lambda_{2}}>0$.

Let

$$
\begin{aligned}
& \lambda_{1 L}^{\prime}=\min \left\{\begin{array}{c}
{\left[\left(c^{2}-2 c-2\right) r^{3}+\left(-2 c^{2}+2 c+5\right) r^{2}-2\left(c^{2}-c+2\right) r+(c-1)^{2}\right] \lambda_{2}^{2}} \\
+\left[-(2 c+3) r^{3}+8 r^{2}-\left(3 c^{2}-6 c+7\right) r+2(c-1)^{2}\right] \lambda_{2}+(1-r)(c+r-1)^{2} \\
\frac{+\sqrt{r(1-r)^{2} c^{2} \lambda_{2}\left\{[(c+2) r+c-1] \lambda_{2}+c+r-1\right\}^{2}\left[(3 r-2) \lambda_{2}+2(r-1)\right]}}{\left[2 \lambda_{2}\left(c^{2}+c+1\right)+1\right] r^{3}+\left[-6 \lambda_{2} c^{2}-2\left(\lambda_{2}-1\right) c-5 \lambda_{2}-3\right] r^{2}} \\
+\left[\left(6 \lambda_{2}+1\right) c^{2}-2\left(\lambda_{2}+2\right) c+4 \lambda_{2}+3\right] r-(c-1)^{2}\left(\lambda_{2}+1\right)
\end{array}\right. \\
& {\left[\left(c^{2}-2 c-2\right) r^{3}+\left(-2 c^{2}+2 c+5\right) r^{2}-2\left(c^{2}-c+2\right) r+(c-1)^{2}\right] \lambda_{2}^{2}} \\
& +\left[-(2 c+3) r^{3}+8 r^{2}-\left(3 c^{2}-6 c+7\right) r+2(c-1)^{2}\right] \lambda_{2}+(1-r)(c+r-1)^{2} \\
& -\sqrt{r(1-r)^{2} c^{2} \lambda_{2}\left\{[(c+2) r+c-1] \lambda_{2}+c+r-1\right\}^{2}\left[(3 r-2) \lambda_{2}+2(r-1)\right]} \\
& {\left[2 \lambda_{2}\left(c^{2}+c+1\right)+1\right] r^{3}+\left[-6 \lambda_{2} c^{2}-2\left(\lambda_{2}-1\right) c-5 \lambda_{2}-3\right] r^{2}} \\
& +\left[\left(6 \lambda_{2}+1\right) c^{2}-2\left(\lambda_{2}+2\right) c+4 \lambda_{2}+3\right] r-(c-1)^{2}\left(\lambda_{2}+1\right)
\end{aligned}
$$




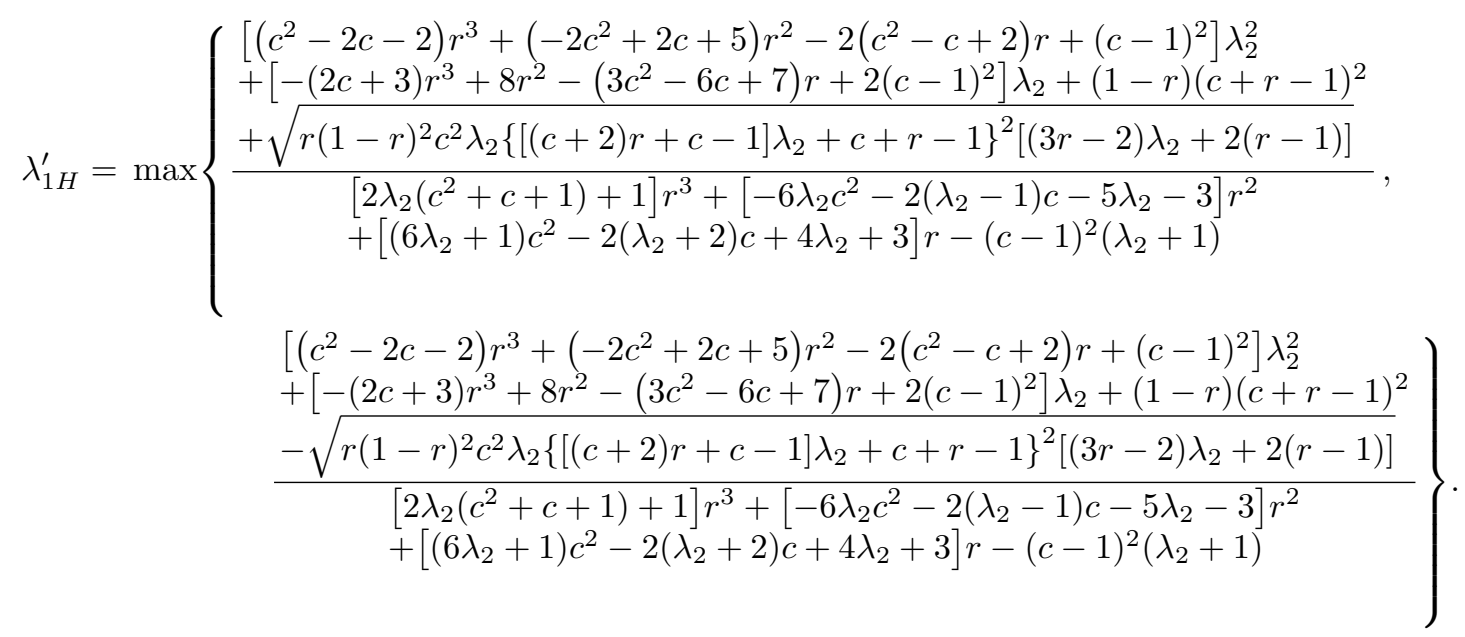

(1) If $r>\frac{2+2 \lambda_{2}}{3 \lambda_{2}+2}$ and $\left[2 \lambda_{2}\left(c^{2}+c+1\right)+1\right] r^{3}+\left[-6 \lambda_{2} c^{2}-2\left(\lambda_{2}-1\right) c-5 \lambda_{2}-3\right] r^{2}+$ $\left[\left(6 \lambda_{2}+1\right) c^{2}-2\left(\lambda_{2}+2\right) c+4 \lambda_{2}+3\right] r-(c-1)^{2}\left(\lambda_{2}+1\right)>0, \frac{\partial \pi_{r 1}^{*}}{\partial \lambda_{1}}>0$.

(2) If $r>\frac{2+2 \lambda_{2}}{3 \lambda_{2}+2}$ and $\left[2 \lambda_{2}\left(c^{2}+c+1\right)+1\right] r^{3}+\left[-6 \lambda_{2} c^{2}-2\left(\lambda_{2}-1\right) c-5 \lambda_{2}-3\right] r^{2}+$ $\left[\left(6 \lambda_{2}+1\right) c^{2}-2\left(\lambda_{2}+2\right) c+4 \lambda_{2}+3\right] r-(c-1)^{2}\left(\lambda_{2}+1\right)<0, \frac{\partial \pi_{r 1}^{*}}{\partial \lambda_{1}}<0$.

(3) If $r<\frac{2+2 \lambda_{2}}{3 \lambda_{2}+2}$ and $\left[2 \lambda_{2}\left(c^{2}+c+1\right)+1\right] r^{3}+\left[-6 \lambda_{2} c^{2}-2\left(\lambda_{2}-1\right) c-5 \lambda_{2}-3\right] r^{2}+$ $\left[\left(6 \lambda_{2}+1\right) c^{2}-2\left(\lambda_{2}+2\right) c+4 \lambda_{2}+3\right] r-(c-1)^{2}\left(\lambda_{2}+1\right)>0, \frac{\partial \pi_{r 1}^{*}}{\partial \lambda_{1}}<0$ when $\lambda_{1 H}^{\prime}>0$ and $\lambda_{1 L}{ }^{+\prime}<\lambda_{1}<\lambda_{1 H}^{\prime}$; otherwise, $\frac{\partial \pi_{r 1}^{*}}{\partial \lambda_{1}}>0$.

(4) If $\quad r \quad<\quad \frac{2+2 \lambda_{2}}{3 \lambda_{2}+2}$ and $\left[2 \lambda_{2}\left(c^{2}+c+1\right)+1\right] r^{3}+\left[-6 \lambda_{2} c^{2}-2\left(\lambda_{2}-1\right) c-5 \lambda_{2}-3\right] r^{2}+$ $\left[\left(6 \lambda_{2}+1\right) c^{2}-2\left(\lambda_{2}+2\right) c+4 \lambda_{2}+3\right] r-(c-1)^{2}\left(\lambda_{2}+1\right)<0, \frac{\partial \pi_{r 1}^{*}}{\partial \lambda_{1}}>0$ when $\lambda_{1 H}^{\prime}>0$ and $\lambda_{1 L}{ }^{+\prime}<\lambda_{1}<\lambda_{1 H}^{\prime}$; otherwise, $\frac{\partial \pi_{r 1}^{*}}{\partial \lambda_{1}}<0$.

Let

$$
\begin{gathered}
\lambda_{2 L}^{\prime}=\min \left\{\begin{array}{l}
\left(\begin{array}{l}
\left.\lambda_{1}+1\right)\left\{\left[\lambda_{1}\left(c^{2}-2 c-2\right)-1\right] r^{3}+\left[\lambda_{1}\left(-2 c^{2}+2 c+5\right)\right] r^{2}+\left[-2\left(c^{2}-1+2\right) \lambda_{1}-c^{2}-1\right] r\right. \\
\left.+\lambda_{1}(c-1)^{2}\right\}+\sqrt{r(1-r)^{2} c^{2}\left(\lambda_{1}+1\right)\left[(3 r-2) \lambda_{1}+r\right]\left\{[(c+2) r+c-1] \lambda_{1}+r\right\}^{2}}
\end{array}\right. \\
{\left[\begin{array}{c}
\left.2 \lambda_{1}\left(c^{2}+c+1\right)+c^{2}+1\right] r^{3}+\left[\left(3 c^{2}-2 c-5\right) \lambda_{1}+2\left(c^{2}-1\right)\right] r^{2} \\
+\left[-2(c-2) \lambda_{1}+c^{2}+1\right] r-(c-1)^{2} \lambda_{1}
\end{array}\right.} \\
\frac{\left(\lambda_{1}+1\right)\left\{\left[\lambda_{1}\left(c^{2}-2 c-2\right)-1\right] r^{3}+\left[\lambda_{1}\left(-2 c^{2}+2 c+5\right)\right] r^{2}+\left[-2\left(c^{2}-1+2\right) \lambda_{1}-c^{2}-1\right] r\right.}{\left[2 \lambda_{1}\left(c^{2}+c+1\right)+c^{2}+1\right] r^{3}+\left[\left(3 c^{2}-2 c-5\right) \lambda_{1}+2\left(c^{2}-1\right)\right] r^{2}+\left[-2(c-2) \lambda_{1}+c^{2}+1\right] r-(c-1)^{2} \lambda_{1}} \\
\left.+\lambda_{1}(c-1)^{2}\right\}-\sqrt{r(1-r)^{2} c^{2}\left(\lambda_{1}+1\right)\left[(3 r-2) \lambda_{1}+r\right]\left\{[(c+2) r+c-1] \lambda_{1}+r\right\}^{2}}
\end{array}\right. \\
\lambda_{2 H}^{\prime}=\min \left\{\begin{array}{c}
\left(\lambda_{1}+1\right)\left\{\left[\lambda_{1}\left(c^{2}-2 c-2\right)-1\right] r^{3}+\left[\lambda_{1}\left(-2 c^{2}+2 c+5\right)\right] r^{2}+\left[-2\left(c^{2}-1+2\right) \lambda_{1}-c^{2}-1\right] r\right. \\
\left.+\lambda_{1}(c-1)^{2}\right\}+\sqrt{r(1-r)^{2} c^{2}\left(\lambda_{1}+1\right)\left[(3 r-2) \lambda_{1}+r\right]\left\{[(c+2) r+c-1] \lambda_{1}+r\right\}^{2}} \\
{\left[2 \lambda_{1}\left(c^{2}+c+1\right)+c^{2}+1\right] r^{3}+\left[\left(3 c^{2}-2 c-5\right) \lambda_{1}+2\left(c^{2}-1\right)\right] r^{2}} \\
+\left[-2(c-2) \lambda_{1}+c^{2}+1\right] r-(c-1)^{2} \lambda_{1}
\end{array},\right.
\end{gathered}
$$




$$
\begin{aligned}
& \left(\lambda_{1}+1\right)\left\{\left[\lambda_{1}\left(c^{2}-2 c-2\right)-1\right] r^{3}+\left[\lambda_{1}\left(-2 c^{2}+2 c+5\right)\right] r^{2}+\left[-2\left(c^{2}-1+2\right) \lambda_{1}-c^{2}-1\right] r\right. \\
& \left.+\lambda_{1}(c-1)^{2}\right\}-\sqrt{r(1-r)^{2} c^{2}\left(\lambda_{1}+1\right)\left[(3 r-2) \lambda_{1}+r\right]\left\{[(c+2) r+c-1] \lambda_{1}+r\right\}^{2}} \\
& \left.\left(c^{2}+c+1\right)+c^{2}+1\right] r^{3}+\left[\left(3 c^{2}-2 c-5\right) \lambda_{1}+2\left(c^{2}-1\right)\right] r^{2}+\left[-2(c-2) \lambda_{1}+c^{2}+1\right] r-(c-1)^{2} \lambda_{1}
\end{aligned} .
$$

(1) If $\quad r>\frac{2 \lambda_{1}}{3 \lambda_{1}+1}$ and $-r\left\{\left[2\left(c^{2}+c+1\right) \lambda_{1}+c^{2}+1\right] r^{3}+\left[\left(3 c^{2}-2 c-5\right) \lambda_{1}+2\left(c^{2}-1\right)\right] r^{2}+\right.$ $\left.\left[2(-c+2) \lambda_{1}+c^{2}+1\right] r-\lambda_{1}(1-c)^{2}\right\}>0, \frac{\partial \pi_{r 1}^{*}}{\partial \lambda_{2}}>0$.

(2) If $r>\frac{2 \lambda_{1}}{3 \lambda_{1}+1}$ and $-r\left\{\left[2\left(c^{2}+c+1\right) \lambda_{1}+c^{2}+1\right] r^{3}+\left[\left(3 c^{2}-2 c-5\right) \lambda_{1}+2\left(c^{2}-1\right)\right] r^{2}+\right.$ $\left.\left[2(-c+2) \lambda_{1}+c^{2}+1\right] r-\lambda_{1}(1-c)^{2}\right\}<0, \frac{\partial \pi_{r 1}^{*}}{\partial \lambda_{2}}<0$.

(3) If $r<\frac{2 \lambda_{1}}{3 \lambda_{1}+1}$ and $-r\left\{\left[2\left(c^{2}+c+1\right) \lambda_{1}+c^{2}+1\right] r^{3}+\left[\left(3 c^{2}-2 c-5\right) \lambda_{1}+2\left(c^{2}-1\right)\right] r^{2}+\right.$ $\left.\left[2(-c+2) \lambda_{1}+c^{2}+1\right] r-\lambda_{1}(1-c)^{2}\right\}>0, \frac{\partial \pi_{r 1}^{*}}{\partial \lambda_{2}}<0$ when $\lambda_{2 H}^{\prime}>0$ and $\lambda_{2 L}{ }^{+\prime}<\lambda_{2}<\lambda_{2 H}^{\prime}$; otherwise, $\frac{\partial \pi_{r 1}^{*}}{\partial \lambda_{2}}>0$.

(4) If $r<\frac{2 \lambda_{1}}{3 \lambda_{1}+1}$ and $-r\left\{\left[2\left(c^{2}+c+1\right) \lambda_{1}+c^{2}+1\right] r^{3}+\left[\left(3 c^{2}-2 c-5\right) \lambda_{1}+2\left(c^{2}-1\right)\right] r^{2}+\right.$ $\left.\left[2(-c+2) \lambda_{1}+c^{2}+1\right] r-\lambda_{1}(1-c)^{2}\right\}>0, \frac{\partial \pi_{r 1}^{*}}{\partial \lambda_{2}}>0$ when $\lambda_{2 H}^{\prime}>0$ and $\lambda_{2 L}^{+\prime}<\lambda_{2}<\lambda_{2 H}^{\prime}$; otherwise, $\frac{\partial \pi_{r 1}^{*}}{\partial \lambda_{2}}<0$.

Acknowledgements. Fund projects: National Natural Science Foundation of China (No. 72071040); Major Program of the National Social Science Foundation of China (21\&ZD118); Major Project for Philosophy and Social Sciences Research in Jiangsu Province (No. 2018SJZDA005); Fundamental Research Funds for the Central Universities (No. 2242021k30005).

\section{REFERENCES}

[1] M.C. Campbell, Perceptions of price unfairness: antecedents and consequences. J. Mark. Res. 36 (1999) $187-199$.

[2] Y.C. Chen, S.C. Fang and U.P. Wen, Pricing policies for substitutable products in a supply chain with internet and traditional channels. Eur. J. Oper. Res. 224 (2013) 542-551.

[3] D. Corsten and N. Kumar, Do suppliers benefit from collaborative relationships with large retailers? An empirical investigation of efficient consumer response adoption. J. Mark. 69 (2005) 80-94.

[4] T.H. Cui, J.S. Raju and Z.J. Zhang, Fairness and channel coordination. Manage. Sci. 53 (2007) $1303-1314$.

[5] A. Dumrongsiri, M. Fan and A. Jain, A supply chain model with direct and retail channels. Eur. J. Oper. Res. 187 (2008) 691-718.

[6] G. Ferrer and J.M. Swaminathan, Managing new and remanufactured products. Manage. Sci. 52 (2006) 15-26.

[7] L. Guo, Inequity aversion and fairness selling. J. Mark. Res. 52 (2015) 77-89.

[8] X. Guo and B. Jiang, Signaling through price and quality to consumers with fairness concerns. J. Mark. Res. 53 (2016) 988-1000.

[9] A. Hagiu and J. Wright, Marketplace or reseller? Manage. Sci. 61 (2014) 184-203.

[10] T. Hendershott and J. Zhang, A model of direct and intermediated sales. J. Econ. Manage. Strat. 15 (2006) $279-316$.

[11] T.H. Ho and J. Zhang, Designing pricing contracts for boundedly rational customers: does the framing of the fixed fee matter? Manage. Sci. 54 (2008) 686-700.

[12] D.A. Kahneman, J.L. Knetsch and R.H. Thaler, Fairness and the assumptions of economics. J. Bus. 59 (1986) $285-300$.

[13] H. Ke and J. Liu, Dual-channel supply chain competition with channel preference and sales effort under uncertain environment. J. Amb. Intel. Hum. Comp. 8 (2017) 781-795.

[14] H. Kurata, D.Q. Yao and J.J. Liu, Pricing policies under direct vs. indirect channel competition and national vs. store brand competition. Eur. J. Oper. Res. 180 (2007) 262-281.

[15] Q.H. Li and B. Li, Dual-channel supply chain equilibrium problems regarding retail services and fairness concerns. Appl. Math. Model. 40 (2016) 7349-7367.

[16] J.J. Liu and H. Ke, Firms' pricing strategies under different decision sequences in dual-format online retailing. Soft. Comput. 24 (2020) 7811-7826.

[17] X.Q. Liu, Y.W. Zhou, Y. Shen, C.M. Ge and J.H. Jiang, Zooming in the impacts of merchants' participation in transformation from online flash sale to mixed sale e-commerce platform. Inf. Manage. 58 (2021) 1-18. 
[18] C.H. Loch and Y.Z. Wu, Social preferences and supply chain performance: an experimental study. Manage. Sci. 54 (2008) $1835-1849$.

[19] B. Mantin, H. Krishnan and T. Dhar, The strategic role of third-party marketplaces in retailing. Prod. Oper. Manag. 23 (2014) 1937-1949.

[20] S. Maxwell, Rule-based price fairness and its effect on willingness to purchase. J. Econ. Psychol. 23 (2002) $191-212$.

[21] H. Oosterbeek, R. Sloof and G.V.D. Kuilen, Cultural differences in ultimatum game experiments: evidence from a meta-analysis. Exp. Econ. 7 (2004) 171-188.

[22] J.K. Ryan, D. Sun and X.Y. Zhao, Competition and coordination in online marketplaces. Prod. Oper. Manag. 21 (2012) 997-1014.

[23] Y.L. Shen, Platform retailing with slotting allowance and revenue sharing. J. Oper. Res. Soc. 69 (2018) $1033-1045$.

[24] H. Stephen and I. Robert, Slotting allowances and retail product variety under oligopoly. Econ. Lett. 158 (2017) 34-36.

[25] L. Tian, A.J. Vakharia and Y.L. Tan, Marketplace, reseller, or hybrid: strategic analysis of an emerging E-commerce model. Prod. Oper. Manag. 27 (2018) 1595-1610.

[26] W. Wang, G. Li and T.C.E. Cheng, Channel selection in a supply chain with a multi-channel retailer: the role of channel operating costs. Int. J. Prod. Econ. 173 (2016) 54-65.

[27] Y. Wen, Y. Wang and B. Dan, Research on multi-channel competition strategy considering introduction of self-operated channel by e-commerce platform and online direct channel by manufacturer. Chin. J. Manage. Sci. 27 (2019) 77-89.

[28] D.Q. Yao and J.J. Liu, Competitive pricing of mixed retail and e-tail distribution channels. Omega-Int. J. Manage. S. 33 (2005) 235-247.

[29] Z. Yi, Y.L. Wang and Y. Liu, The impact of consumer fairness seeking on distribution channel selection: direct selling vs. agent selling. Prod. Oper. Manag. 27 (2018) 1148-1167.

[30] R. Yoshihara and N. Matsubayashi, Channel coordination between manufacturers and competing retailers with fairness concerns. Eur. J. Oper. Res. 290 (2021) 546-555.

[31] J. Zhao, L. Liu and Y. Wang, Research on competition and mode selection of suppliers based on e-commerce platform. Syst. Eng. Theor. Prac. 39 (2019) 2058-2069.

\section{Subscribe to Open (S20) A fair and sustainable open access model}

This journal is currently published in open access under a Subscribe-to-Open model (S2O). S2O is a transformative model that aims to move subscription journals to open access. Open access is the free, immediate, online availability of research articles combined with the rights to use these articles fully in the digital environment. We are thankful to our subscribers and sponsors for making it possible to publish this journal in open access, free of charge for authors.

\section{Please help to maintain this journal in open access!}

Check that your library subscribes to the journal, or make a personal donation to the $\mathrm{S} 2 \mathrm{O}$ programme, by contacting subscribers@edpsciences.org

More information, including a list of sponsors and a financial transparency report, available at: https://www. edpsciences.org/en/maths-s2o-programme 